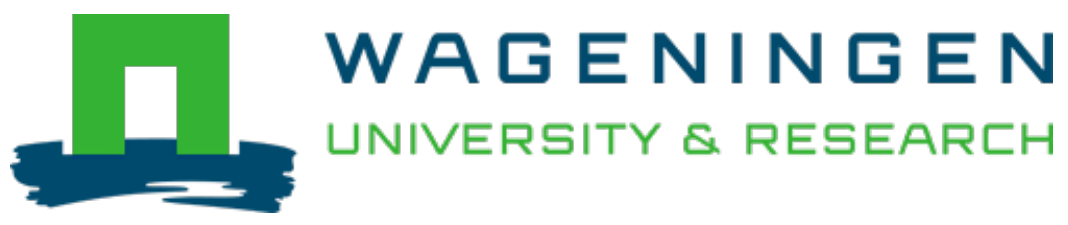

\title{
Reducing the incidence of allergy and intolerance to cereals
}

\author{
Journal of Cereal Science
}

Gilissen, L.J.W.J.; Meer, I.M.; Smulders, M.J.M.

https://doi.org/10.1016/j.jcs.2014.01.005

This article is made publicly available in the institutional repository of Wageningen University and Research, under the terms of article $25 \mathrm{fa}$ of the Dutch Copyright Act, also known as the Amendment Taverne. This has been done with explicit consent by the author.

Article $25 \mathrm{fa}$ states that the author of a short scientific work funded either wholly or partially by Dutch public funds is entitled to make that work publicly available for no consideration following a reasonable period of time after the work was first published, provided that clear reference is made to the source of the first publication of the work.

This publication is distributed under The Association of Universities in the Netherlands (VSNU) 'Article $25 \mathrm{fa}$ implementation' project. In this project research outputs of researchers employed by Dutch Universities that comply with the legal requirements of Article $25 \mathrm{fa}$ of the Dutch Copyright Act are distributed online and free of cost or other barriers in institutional repositories. Research outputs are distributed six months after their first online publication in the original published version and with proper attribution to the source of the original publication.

You are permitted to download and use the publication for personal purposes. All rights remain with the author(s) and / or copyright owner(s) of this work. Any use of the publication or parts of it other than authorised under article $25 \mathrm{fa}$ of the Dutch Copyright act is prohibited. Wageningen University \& Research and the author(s) of this publication shall not be held responsible or liable for any damages resulting from your (re)use of this publication.

For questions regarding the public availability of this article please contact openscience.library@,wur.nl 
Review

\title{
Reducing the incidence of allergy and intolerance to cereals
}

\author{
Luud J.W.J. Gilissen ${ }^{\mathrm{a}, *}$, Ingrid M. van der Meer ${ }^{\mathrm{a}}$, Marinus J.M. Smulders ${ }^{\mathrm{b}}$ \\ ${ }^{a}$ Plant Research International, Wageningen UR, P.O. Box 16, 6700 AA Wageningen, The Netherlands \\ ${ }^{\mathrm{b}}$ Wageningen UR Plant Breeding, P.O. Box 16, 6700 AA Wageningen, The Netherlands
}

\section{A R T I C L E I N F O}

\section{Article history:}

Received 24 September 2013

Received in revised form

9 January 2014

Accepted 13 January 2014

\section{Keywords:}

Bakers' asthma

Coeliac disease

Gluten-free

Knowledge framework

Prevention

\begin{abstract}
A B S T R A C T
This paper reviews studies on allergy, intolerance and sensitivity to cereals, especially to wheat, barley, rye, maize, rice and oats with regard to reducing their incidences. Prevalence of allergy to cereals is generally low; prevalence of other cereal-related diseases are highest for wheat and lowest for oats. Compared to the other cereals, wheat (and its components wheat starch and vital gluten) are most abundantly applied in a broad range of food products world-wide, which justifies the major focus of this review on wheat. Current knowledge on diagnosis of the cereal-related diseases and on detection and characterization of the relevant proteins is discussed in the context of the development of prevention strategies. Aiming at their design and implementation, such strategies require building of knowledge frameworks at the primary, secondary and tertiary prevention levels. In this regard, selection and breeding of low-allergenic/low-intoleragenic crop varieties, application of processing and technological approaches, and the introduction of alternative safe cereal crops is discussed. Sustainable reduction of immune-related diseases in general (including cereal allergies and intolerances) is discussed with regard to eating habits and lifestyle factors, human genetic and physiological characteristics, and the role of the intestinal micro-flora.
\end{abstract}

\section{Introduction}

During recent decades, allergies and certain food intolerances have shown a worldwide gradual increase in prevalence, concomitantly with economic growth, urbanization, and changes in lifestyle and dietary patterns. They are triggered in humans with an unbalanced immune system and intestinal micro-flora by specific animal and plant proteins present in a variety of foods including cereals. Allergies are generally violent immune reactions, whereas symptoms of intolerances are mainly chronic.

Cereals contain various types of proteins, including watersoluble albumins, saline-soluble globulins, alcohol-soluble prolamins, and insoluble glutenins. The absolute and relative amounts

Abbreviations: ATI, Amylase trypsin inhibitor; CD, Coeliac disease; DBPCFC, Double-blind placebo-controlled food challenge; ELISA, Enzyme-linked immunosorbent assay; HLA (DQ2/8), Human leucocyte antigen; IgE, IgA, IgG, Immunoglobulin E, A, G; LC-MS, Liquid chromatography-mass spectrometry; LTP, Lipid transfer protein; mAb, Monoclonal antibody; ncGS/ncWS, Non-coeliac gluten sensitivity/non-coeliac wheat sensitivity; OAS, Oral allergy syndrome; PR proteins, Pathogenesis-related proteins; SPT, Skin prick test; T1D, Type 1 diabetes; TCC, T cell clone; TG2, tTG, Tissue transglutaminase; Th1, Th2, Th17, Treg cells, thymus-derived types of T-helper cells; WGA, Wheat germ agglutinin.

* Corresponding author. Tel.: +31 317 480983; fax: +31 317418094.

E-mail addresses: luud.gilissen@wur.nl (L.J.W.J. Gilissen), ingrid.vandermeer@ wur.nl (I.M. van der Meer), rene.smulders@wur.nl (M.J.M. Smulders). of these protein types vary considerably among cereals, as do their digestibility and immunogenicity.

The prevalence of allergies to cereals is low, although no exact frequencies are known. Most commonly mentioned, and described in this review, are allergies to wheat, maize and rice, of which occupational bakers' asthma has the highest economic impact. Lipid transfer protein, $\omega$-5-gliadin and amylase trypsin inhibitor, all related proteins in the prolamins superfamily, are the causal proteins. Sensitization (i.e. the presence of specific IgE in serum without clinical symptoms) involves a wider variety of protein types, mainly known from wheat, and affects about $2 \%$ of the population. Sensitizing and allergenic proteins are generally identified through IgE binding.

Cereal intolerance occurs at a prevalence of $1-3 \%$ of the population worldwide, but varies between countries. The causal proteins are the gliadins and the glutenins from wheat and related proteins from barley and rye, together commonly called 'gluten'. Gluten intolerance (or coeliac disease, $\mathrm{CD}$ ) is classified as an auto-immune disease and occurs in individuals with the human leucocyte antigen (HLA) DQ2 and/or DQ8 genotype. The increase of wheat gluten consumption, especially through the worldwide increased application of 'vital gluten' in a broad variety of food products and through increased consumption of wheat flour-based products, may have contributed to the increased prevalence of $C D$ during the last decades since the 1950s. 
Recently, rapid and significant growth has been observed in the number of consumers embracing a gluten-free or wheat-free diet. No clear and unambiguous medical and scientific symptoms are yet available to consider this so-called 'non-coeliac gluten sensitivity' (ncGS; also known as non-coeliac wheat sensitivity, ncWS) as a new health threat. A correlation with IBS (Irritable Bowel Syndrome) is suggested.

To develop strategies for reduction of the incidence of cereal allergy and intolerance, we review the most up to date information on (1) the diagnosis of the diseases and (2) the detection and characterization of the relevant proteins. Cereal allergies are reliably tested by skin-prick tests and (double-blind placebocontrolled) food challenges. For ncGS, a wheat/gluten elimination diet is currently the only diagnostic tool. CD is diagnosed according to five well-defined criteria, but it is thought that only about $10 \%$ of the total CD population has been diagnosed properly. Because of the chronic character and the high diversity of the symptoms, misdiagnosis often occurs. Many undiagnosed individuals, unaware they may have $C D$, accept their chronic state of ill health as normal. Nevertheless, this large group forms a significant societal issue in terms of prevention.

In $C D$, the gliadins and glutenins form a complex mixture of proteins from different protein families, of which most carry one or more of the 31 internationally agreed HLA-DQ2 and -DQ8 epitopes. Measuring $\mathrm{CD}$ toxicity depends on the identification and quantification of the immunogenicity (number and clinical impact of the various epitopes) of a cereal cultivar or a cereal-derived food product. By far the most $C D$-toxic epitopes are known from the gliadins (especially from the $\alpha$-gliadins). Diagnostic tools available are monoclonal antibodies, $\mathrm{T}$ cells, genomics and proteomics analysis, and reference material and volunteers are required.

Knowledge built on diagnostic and detection/characterization data enables the development of a framework to design and implement prevention strategies at the primary, secondary and tertiary levels. We have reviewed in particular the possibilities for prevention by (1) searching for low CD-toxic wheat varieties via selection, breeding, mutation and genetic modification (deletion and silencing of gluten gene loci); (2) production of safe cereal foods through processing and other technological approaches, such as sourdough fermentation, specifically removing gliadins from gluten extracts, the development of gluten alternatives for applications in food improvement, and increasing the overall quality and reliability of gluten-free food products; and (3) the introduction of safe alternative cereals into the gluten-free diet, with special emphasis on oats. These strategies may result in better balancing of, in particular, the use of wheat (gluten) with food safety. In this regard, the overall growing interest in gluten-free foods should be considered a positive challenge to the food industry for productinnovation. A sustainable reduction in the incidence and the prevalence of immune-related diseases, including cereal allergy and intolerance, will require increasing the knowledge and understanding of the interactions between the three major pillars: the food (eating pattern and lifestyle), human genetics and physiology, and the intestinal micro-flora.

Developed societies, which until the 1940s struggled with infectious diseases, are now confronted with rapid increases in chronic diseases, such as type 2 diabetes, obesity, heart and vascular diseases, hypertension, cancers, allergies and autoimmune related diseases (Rook, 2011). The western lifestyle, which is characterized by limited exercise, over-consumption of, in particular, highly-refined processed foods and sugar-sweetened beverages, high levels of hygiene, widespread use of antibiotics, and stress, apparently has far reaching impacts on human physiology, the immune system and the composition of the intestinal micro-flora. About a quarter of the population in Europe, USA and
Japan suffers from allergies and intolerances (UCB, 1997; Gao et al., 2012). The allergy burden in developing countries (China, India, Brazil) is also increasing concomitantly with economic growth, urbanization and lifestyle transitions (Gao et al., 2012). This burden needs to be reduced worldwide. In this review we focus on cerealinduced allergies and intolerances, and on strategies for their prevention.

\section{Cereal allergies and intolerances/sensitivities}

\subsection{Cereal allergies}

Allergy ('allos' = other; 'ergon' = to work) in the narrow sense refers to aberrant and violent reactions of the immune system towards generally harmless compounds (mostly proteins from environmental sources such as pollen, house dust, food-industrial dust, from the surfaces of living plants and animals, from insect stings and from food sources) that are normally tolerated by the immune system. In these reactions, immunoglobulin E (IgE) acts as the mediating antibody in the immediate development of inflammatory responses or even life-threatening anaphylaxis. The symptoms occur especially in those body regions that are in contact with the outside world: lungs $\left(80 \mathrm{~m}^{2}\right)$, skin $\left(2 \mathrm{~m}^{2}\right)$ or digestive tract $\left(300 \mathrm{~m}^{2}\right)$, and include asthma, hay fever, eczema, oral allergies, food and contact allergies, and sometimes combinations of these. Anaphylaxis is a systemic reaction.

Allergic responses involve several steps and immune cell types. Antigen-presenting cells (present in all body surfaces) expose a part of a protein in its linear form to T cells (Th2 cells). When these T cells recognize this protein part (T cell-epitope) as originating from a harmful source (antigen), they will activate B cells to produce and release antigen-specific IgE that can bind the antigen through recognition of (generally) conformational epitopes (B cell- or IgEepitopes) at the surface of the antigen. The next steps of the sensitization process include the loading of mast cells with antigenspecific IgE. An allergic response requires a repeated contact with the antigen, causing IgE bridging on the surface (IgE receptors) of the mast cells through its double IgE-binding valence, upon which the mast cell will release mediators (histamines, etc.) that cause the allergic inflammation or anaphylaxis. Not all antigens have double valence, which would enable them to bridge two IgEs, and so these can only cause sensitization. Some individuals, due to genetic predisposition combined with environmental factors, produce relatively high amounts of IgE and are called 'atopic'. These individuals are prone to becoming sensitized or to developing a real allergy.

Plant food allergens fall largely within a limited number of protein (super) families that are characterized on the basis of structural and functional properties. These superfamilies are: the cupins (globulin proteins such as vicilins and legumins in nuts, soy and peanut), the prolamins (high in proline and glutamine with conserved cysteine residues: prolamins in cereal grains; $2 \mathrm{~S}$ albumins in nuts; non-specific lipid transfer proteins [LTP] in fruits, nuts, cereal seeds, vegetables; amylase- and protease-inhibitors in cereals) and profilins (structural proteins in all eukaryotic cells) (Shewry and Halford, 2002; Breiteneder and Radauer, 2004). Next to these families, several types of plant pathogenesis-related (PR) proteins include allergens. PR proteins are a collection of unrelated proteins that function in the defence system of higher plants in general, and include proteins belonging to one of the previous allergen groups. Lectins (carbohydrate-binding proteins present in most plants, such as wheat germ agglutinin, WGA) may also cause adverse health effects, including allergy, but sound data are lacking. Lectins generally lose their structure and biological activity upon heating (Matucci et al., 2004). 
Cereal grain proteins (from wheat, barley, rye, maize, rice, oats, sorghum, and various species of millet) include water-soluble albumins, saline-soluble globulins and alcohol-soluble prolamins (which include gliadins and glutenins in wheat). Representative proteins of all of these groups have been proposed as potential allergens in several of the species mentioned. Regarding cereal allergy, the most widely suggested sources are wheat, maize, and rice. Beer (barley) allergy is rare; the causal proteins have been identified as nsLTP (non-specific lipid transfer protein; Quercia et al., 2012) and serpin protease inhibitor Z (Garcia-Casado et al., 2001; Tatham and Shewry, 2008). Analyses of IgE in sera from patients with atopic dermatitis have shown strong cross-reactivity of several proteins of different molecular weight (MW) between wheat, rye and barley, reflecting their taxonomic relationships (Varjonen et al., 1994). Oat food allergy is also a rare, delayed-type, cell-mediated allergy, limited to infancy (Sicherer and Sampson, 2010). At the IgE level, oat flour showed only weak crossreactivity with wheat, rye and barley. Non-specific IgE binding in oats and also in wheat, rye and barley was ascribed to the presence of a $66 \mathrm{kDa}$ protein, probably a lectin (Varjonen et al., 1994). Contact allergy to cosmetic moisturizers containing oat protein for their presumed or demonstrated anti-inflammatory role may occur in young children (under two years of age) with atopic dermatitis who have an immature epidermal barrier but the protein(s) involved have not yet been identified (Boussault et al., 2007). Below, we describe the most common cereal allergies (see also Table 1 ).

\subsubsection{Wheat allergy}

Wheat allergy is generally related to common bread wheat, Triticum aestivum, which dominates world wheat production. Wheat allergy is considered a rare allergy. A systematic review on food allergies indicated a prevalence of sensitization to wheat of $2.0 \%$ (from a total of four studies: $88 / 4470$ adults, with highest scores of $3.6 \%$ in the USA) as assessed by $\operatorname{IgE}$, while wheat food challenge tests revealed an overall prevalence of the actual allergy of $0.25 \%$ (from a total of five studies: $7 / 2809$ children younger than 14 years) (Zuidmeer et al., 2008). In children, wheat allergy symptoms are mainly atopic eczema (dermatitis), vomiting, and sometimes anaphylaxis.

The relatively high frequency of wheat sensitization includes almost thirty antigens (including potential allergens) from different protein families. It should be mentioned here that sensitisation does not necessarily lead to clinical symptoms after re-contact with the allergen, but indicates allergenic potential (see below under 3 . Diagnostics). These thirty antigens include various water-soluble proteins such as amylase inhibitors (e.g. amylase trypsin inhibitor, ATI) and xylanase inhibitors that have been identified as major allergens. These can sensitize gastro-intestinally and through inhalation, and can be involved in bakers' asthma and cereal food allergy (Pastorelli et al., 2002 and references therein). Furthermore, LTP (nsLTP) is a known pan-allergen from many plant sources that can act as food and inhalation allergen, and is a well-known crossreactive allergen, as well as thaumatin-like protein, and chitinases

Table 1

List of major cereal allergens and their related allergy type.

\begin{tabular}{cllllll}
\hline Cereal/allergen & Wheat & Barley & Rye & Maize & Rice & Oats \\
\hline $\begin{array}{c}\text { Lipid transfer } \\
\text { protein }\end{array}$ & $\begin{array}{l}\text { Food allergy; } \\
\text { bakers' asthma }\end{array}$ & $\begin{array}{l}\text { Food } \\
\text { allergy }\end{array}$ & - & $\begin{array}{l}\text { Food } \\
\text { allergy }\end{array}$ & Food & - \\
allergy & & - \\
& $\begin{array}{l}\text { Wheat-dependent } \\
\text { exercise-induced } \\
\text { anaphylaxis }\end{array}$ & $\begin{array}{l}\text { Food } \\
\text { allergy }\end{array}$ & $\begin{array}{l}\text { Food } \\
\text { allergy }\end{array}$ & $\begin{array}{l}\text { Food } \\
\text { allergy }\end{array}$ & - & - \\
$\begin{array}{c}\text { Amylase trypsin } \\
\text { inhibitor }\end{array}$ & $\begin{array}{l}\text { Food allergy; } \\
\text { bakers' asthma }\end{array}$ & $?$ & $?$ & $\begin{array}{l}\text { Food } \\
\text { allergy }\end{array}$ & - & - \\
\hline
\end{tabular}

that have been mentioned in this context (Tatham and Shewry, 2008; Sotkovský et al., 2011). All these proteins may take part in specific IgE production and sensitization in sensitive (atopic) individuals. Apart from water-soluble wheat proteins, proteins from other solubility groups are known to be involved in bakers' asthma and wheat food allergies in adults and children. Bakers' asthma and wheat food allergy generally involve different proteins, with the exception of amylase inhibitors, peroxidase, gluten proteins and especially nsLTP, which can be active in both allergy types (Tatham and Shewry, 2008, and references therein; Battais et al., 2008; Salcedo et al., 2011). Remarkably, limited IgE cross-reactivity between wheat LTP and LTPs from other food sources (e.g. peach) has been found (Palacin et al., 2007), which is different from maize allergy (see below). However, cross-reactivity between wheat flour allergens and other cereal allergens (from barley, rye, rice and maize) and grass pollen allergens does exist as common IgEreactivity has been identified (Sotkovský et al., 2011). Although several glutenins are known allergens, the most severe allergic symptoms are associated with the gliadins. IgE-cross-reactivity with $\gamma$-secalin of rye and $\gamma$-hordein of barley suggests that wheat $\omega-5$ gliadin is the primary sensitizer (Pastorelli et al., 2002) of wheat-dependent exercise-induced anaphylaxis (WDEIA), of which the relevant epitopes have been listed (Tatham and Shewry, 2008). Although oat avenins have a relatively high sequence similarity to wheat $\omega$-gliadins, they have never been found to be linked to WDEIA.

\subsubsection{Maize allergy}

Allergic reactions to maize have been reported in southern Europe, Mexico and the USA. The prevalence of maize allergy is low but the exact frequency has not been established. The major food allergens in maize are $\alpha$-amylase inhibitor and LTP (Pastorello et al., 2000 , 2009). In contrast to wheat LTP, maize LTP is known to induce allergic cross-reactivity with the LTPs found in other cereals (barley, rice) and in fruits (cherry, peach). Maize-allergic individuals are, therefore, different from typical cereal-allergic patients who have wheat allergy with allergic cross-reactivity to barley and rye (Scibilia et al., 2008; Venter et al., 2008). Sera of maize-allergic patients bind to various new allergens: vicilin, globulin-2, $\gamma$-zein (homologous to wheat gliadins), endochitinases, thioredoxins and trypsin inhibitor (Fasoli et al., 2009). The symptoms of maize allergy are those common in food allergy, but according to the type of environmental exposure, dietary habits and pre-existing sensitizations, maize allergy can also involve respiratory symptoms, occupational asthma and dermatitis; some cases of anaphylaxis have also been reported (Pastorello et al., 2009). Thioredoxins, known as minor food allergens of maize, have proved to be a crossreactive cereal allergen family related to bakers' asthma, and may also be related to grass pollen allergy (Weichel et al., 2006).

\subsubsection{Rice allergy}

Rice allergy is rare in western countries. Anaphylaxis caused by rice consumption may occur in LTP-allergic patients, indicating that rice should be also considered a potential cause of allergy. Three cases of rice-induced anaphylaxis in LTP-allergic patients have been reported. In vitro inhibition studies, carried out using LTP purified from rice and apple as well as whole peach extract, showed that LTP was the relevant allergen in these patients and demonstrated the cross-reactivity between rice LTP and peach and apple LTPs (Asero et al., 2007). Recently, an increase in the number of patients sensitized to rice allergens with or without clinical symptoms has been reported in Asian countries (Japan, Korea), with LTP as a candidate major allergen (Jeon et al., 2011). 


\subsection{Cereal intolerance and sensitivity}

\subsubsection{Coeliac disease $(C D)$}

Allergy, in the formal definition, includes the presence of $\operatorname{IgE}$ antibodies against the allergen. When considered more broadly, cereals may also cause food intolerance, in which there is a specific reaction to cereal components (i.e. prolamin storage proteins in the seeds of wheat (gluten), barley (hordein) and rye (secalin)) without the occurrence of specific IgE antibodies but with increased T-cell activity (Mills et al., 2013). Under normal physiological conditions, the immune system in the gut develops a tolerance against the vast majority of food proteins, including gluten. Individuals that express the human leucocyte antigen (HLA) DQ2 and/or DQ8 (which includes about one third of the population; Troncone et al., 2008) can be intolerant to gluten proteins and may develop coeliac disease (CD), a chronic inflammation of the small intestine that occurs as a response to continuous consumption of gluten, which leads to a variety of symptoms ranging from bowel to skin, bone, nerve and muscle complaints. The, still increasing, prevalence of $C D$ is $1-3 \%$ of the general population worldwide (Lindfors et al., 2012, and references therein), but it varies from country to country. The immunogenic gluten fragments that cause $C D$ in many patients have been identified (Sollid et al., 2012).

$\mathrm{CD}$ is classified as an auto-immune disease because of the involvement of auto-antibodies (i.c. IgA and IgG against tissuetransglutaminase (TG2), of which the IgAs have the highest disease specificity), and the occurrence of auto-reactive intra-epithelial lymphocytes (Sollid and Jabri, 2005). Auto-antibodies were also observed in extra-intestinal manifestations of $C D$, such as gluten ataxia and dermatitis herpetiformis. In the latter case, next to TG2 antibodies, antibodies have been identified against TG3, a transglutaminase that is uniquely expressed in the dermal papillae in these patients (Sollid and Jabri, 2005).

\subsubsection{Gluten-related type 1 diabetes (T1D)}

It has been suggested that the increased intake of glutencontaining products across the world is also one of the triggers to the development of type 1 diabetes. Undiagnosed $C D$, disturbing the intestinal barrier to large protein molecules (gluten) and enteric viruses, may be the start of T1D (Frisk et al., 2008). The prevalence of CD in patients with T1D is $\sim 20$ times higher than in the general population; $60 \%$ of the patients with both diseases initially started with
$\mathrm{CD}$, while the other $40 \%$ developed $\mathrm{CD}$ a few years after the onset of T1D (Barera et al., 2002). This shared pathogenesis also shares the genetics of auto-immune-related diseases (Zhernakova et al., 2009).

\subsubsection{Non-coeliac wheat/gluten sensitivity (ncWS; ncGS)}

Recently, the spectrum of wheat/gluten-related disorders was analysed by Sapone et al. (2012) (Fig. 1). Of particular interest is the rapid growth of the population embracing a gluten-free diet: the gluten-free food market shows an annual increase of 25-30\%, and by now represents an annual market value of almost $€ 2.5$ billion worldwide. Although it is clear from medical observations that not all of these consumers need a gluten-free diet for medical reasons, this gradual increase indicates that the number of people who feel comfortable on this diet exceeds by far the number of diagnosed CD and wheat allergic patients (Sapone et al., 2012). Analysis of 200 million restaurant visits in US showed that almost 30\% of adult customers claimed to cut down on or avoid gluten completely (NPD, 2013). In clinical practice this has led to a diagnostic problem because many of these people lack serological and duodenal biomarkers, which raised the question whether sensitivity to wheat, gluten or other wheat-related compounds beyond CD really exists, or what the observed health effects may be, as there are large correlated changes in the diet excluding fast food and switching to different food products.

Two independent studies recently suggest that ncWS exists. In a double-blind placebo-controlled re-challenge trial, patients with irritable bowel syndrome (IBS) in whom CD was excluded and who were symptomatically controlled on a gluten-free diet, were significantly worse for overall symptoms within one week after starting gluten consumption (Biesiekierski et al., 2011). Another study diagnosed 276 patients with IBS-like presentations in a double-blind placebo-controlled challenge and confirmed the existence of ncWS as a clinical condition different from CD (Carroccio et al., 2012). Interestingly, the data in this study also suggested the existence of two distinct populations of subjects with ncWS: one group with characteristics more similar to $\mathrm{CD}$, and the other group with characteristics pointing to food allergy with additional sensitivities to e.g. cows' milk (Carroccio et al., 2012). This is consistent with a study on wheat ATIs (Junker et al., 2012). These pathogenrelated proteins appeared to be strong indicators of the innate immune responses of several cell types (monocytes, macrophages and dendritic cells) of the immune system in coeliac as well as in

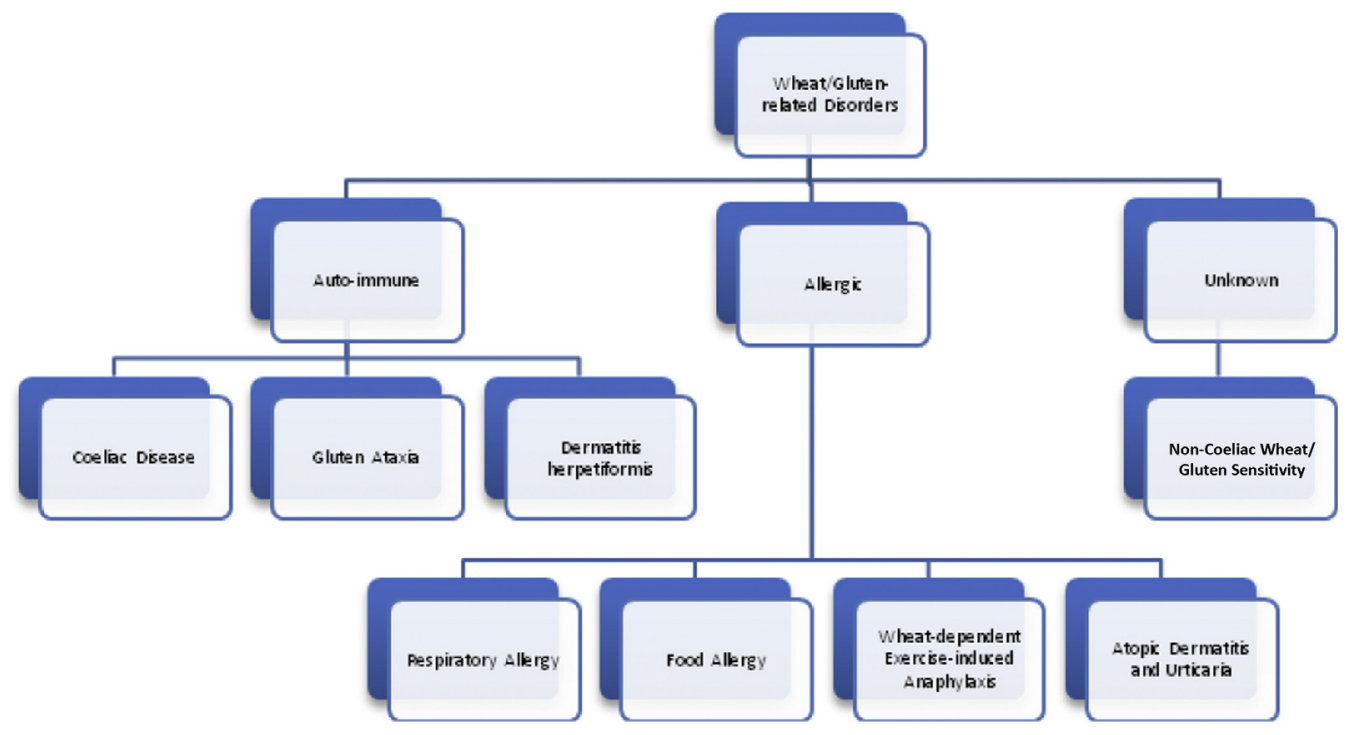

Fig. 1. Classification of wheat- and gluten-related disorders (after Sapone et al., 2012; Gilissen et al., 2013a). 
non-coeliac patients. These findings define cereal ATIs as novel (innate) contributors to coeliac disease. It was suggested that these ATIs may also fuel inflammation and immune reactions in other intestinal and non-intestinal immune disorders. Nevertheless, the absence of clear biomarkers and knowledge on the aetiology, the high frequency of self-reported ncWS, and the fact that gluten-free is turning into an internet trend, emphasises the need for a reliable and sound diagnosis, and shows that we have no information about the prevalence in the population, although, in correlation to IBS data (Carroccio et al., 2012), a prevalence of 5-10\% of the population has been suggested (Brouns et al., 2013). Furthermore, other explanatory factors should be (re)considered, such as abdominal discomfort due to regular fermentation processes that occur in all (healthy) individuals.

We can conclude that the issue of ncWS is complex, and that various stakeholders take different positions and have different interests. From a medical point of view, further investigations of the causes, the aetiology, the independent disease status, the clinical relevance and the possibilities for prevention of gluten sensitivity are required. According to current knowledge, ncWS can best be considered an inconvenience that can be avoided by reduced gluten consumption or a gluten-free diet. At present there are no clear and unambiguous signs that ncWS represents a new health threat to the population, although the rapid increase in the general demand for gluten-free foods would suggest differently. The glutenfree food industry now advertises with the intent to expand the market beyond $\mathrm{CD}$ patients. This is a positive change for the glutenintolerant and sensitive population and also for potential and undiagnosed $C D$ patients, as well as a challenge to the food industry to design and develop innovative healthy, nutritious, safe and sustainable food products from sources other than wheat and related cereals.

\subsubsection{Versatility of wheat and gluten, and the choice for a gluten- free diet}

Wheat is widely grown and consumed. It is the second largest crop annually produced and consumed ( $\sim 650$ million tonnes), and supplies about $20 \%$ of the world's calories. Wheat has the largest global production area ( $\sim 240$ million ha) and the largest volume of a single crop traded internationally ( $\sim 140$ million tonnes) (USDA, 2013; Wikipedia, 2013). Its qualities have been recognized since ancient times. Palaeolithic people already consumed cereals as processed foods, as shown by remains found on grinding stones (Piperno et al., 2004; Wrangham et al., 2009) long before they were domesticated (maybe even Neanderthals cooked cereals [probably barley]; Fresco, 2012). Cereals were one of the major factors in the 'escape' of humanity from the Palaeolithic 'paradise'. The physicochemical properties of flour and dough make wheat highly popular in all kinds of food applications. In many wheat-based foods, such as bread and bakery products, pasta, pizza, noodles, and breakfast cereals, the presence of wheat is evident. But it is increasingly being used as a hidden ingredient in a large number and diversity of food items, mainly since the 1960s, and especially since the 1990s. These include soups and sauces, dressings, snacks, jams and spreads, candy and chocolates, and processed herbs and spices. Wheat can also be present in many processed meat products, frozen poultry, fish and vegetables, ice creams, and popcorn. As a result, currently more than $30 \%$ of packed supermarket food items contain wheat or wheat-derived constituents, especially wheat gluten and wheat starch. These applications are still increasing rapidly (Atchison et al., 2010). The network forming properties of wheat gluten means that it is highly versatile in food technological applications. All western consumers eat wheat/gluten-containing foods in large amounts; the daily gluten intake is about $20 \mathrm{~g}$, with segments of the population consuming up to $50 \mathrm{~g}$ (Sapone et al., 2012, and references therein; Gilissen et al., 2013a).
It has also been suggested that gluten-free diets could be harmful for people who do not have $C D$, as gluten-free diets in western society are generally poor in, amongst others, dietary fibre (Aziz et al., 2012; Elli, 2012; Di Sabatino et al., 2013). The nutritional value and quality of the gluten-free diet is currently receiving increasing attention (Lee et al., 2009; Arendt et al., 2011) and is rapidly becoming an equivalent to gluten-containing diets.

\subsubsection{Wheat and immune interactions}

When discussing wheat allergy, we have already noted that various wheat proteins have immunogenic (sensitizing) potential rather than causing real allergic reactions (Sotkovský et al., 2011), and that the prevalence of sensitization is much higher than the prevalence of wheat allergies (occurrence of clinical symptoms) (Zuidmeer et al., 2008). Together the immunogenicity of the specific protein and the sensitization of the individual host reflect an immune interaction in which a change in the complex balances within the immune system occurs, possibly in combination with changes in the cross-talk of the immune system with the diversity of intestinal micro-organisms in the gut micro-flora. Food components, the immune system and the gut micro-organisms form an interactive system. These may lead to changes in the production and balance of specific cytokines and their signalling activities, but do not necessarily result in complaints or clinically relevant symptoms after renewed contact with the immunogenic protein/peptide (antigen). In this respect it is of interest that allergy (Th2-mediated) and auto-immunity (Th1-mediated) do not necessary exclude each other (Kidd, 2003), as had been commonly accepted for many years. Upon complex immunogenic stimulation, the differentiation of CD4+ T cells is not restricted to a small number of well-defined T cell phenotypes (Th1, Th2, Th17, Treg), but rather operates through a continuum of mixed-phenotype states in which the levels of T cell lineage-specific activities change with the levels of the stimulation, leading to a continuously tuneable cell state (Antebi et al., 2013). This may bring wheat allergy, $\mathrm{CD}$, and maybe also wheat/gluten sensitivity, closer together and emphasize the complex immunogenic composition of the wheat food matrix. Another complex immunological phenomenon is peanut allergy, in which a series of allergens is involved (Ara $h$ 1-7) representing different protein families, and including both Th1 and Th2 phenomena in a murine model (Van Wijk et al., 2004). Allergies and intolerances to wheat may now also be studied in this broader context, beyond the Th1/ Th2 balance. Some authors have suggested that restoring the microbial flora towards the complexity found in poor rural communities may already be effective in reducing the incidence of allergy and auto-immune related diseases (Rook, 2012).

\section{Diagnostics}

\subsection{Allergy}

In allergy, sensitization can have been taken place without further consequences for the development of clinical symptoms after repeated contacts with the allergen and is defined as the presence of a specific IgE response occurring upon exposure of the immune system to an allergen. Allergen-specific IgE can be detected in serum (in vitro assays) and in skin-prick tests (SPT) in which allergens applied subcutaneously provoke mast cells (loaded with allergen-specific IgE on their surface receptors) to release their mediators (histamines, etc.) causing inflammation of the skin. Many years of daily medical practice have demonstrated that these in vitro and skin-prick tests are unable to reliably predict clinically relevant allergy (i.e. the occurrence of clinical symptoms upon contact with the allergen): they just measure sensitization (Asero et al., 2007). SPT responses may occur due to cross-reactivity of 
IgE, especially in atopic individuals that, by genetic predisposition, produce relatively high amounts of IgE. The most reliable test to identify clinical relevance and to predict clinical symptoms is the double-blind placebo-controlled food challenge (DBPCFC). The reliability of this test is high, but it may result in false-negative responses in cases of food (wheat) dependent exercise-induced anaphylaxis, because these responses only occur if the ingestion of the responsible food is followed by exercise within a time period between a few minutes to $3 \mathrm{~h}$, and require other cofactors to increase intestinal absorption (Asero et al., 2007).

The clinical presentations of food allergy can include the oral allergy syndrome (OAS; IgE-mediated contact urticaria involving lips, tongue, palate, throat, ears, nose, eyes) which generally has mild symptoms. Commonly, OAS occurs after sensitization with pollen allergens (e.g. birch and grasses, the latter being relevant in cereal allergies) and subsequent cross-reactivity involving homologous proteins in fresh foods (especially fruits, nuts with birchrelated proteins) and grasses (the allergens involved are generally labile to heating and processing makes them easily digestible). Grass pollen and cereal food cross-reactivity has been described for profilin (Constantin et al., 2009). Stable allergens can also be involved in OAS with further gastrointestinal response, as was observed in maize-allergic cases (Scibilia et al., 2008).

Cereal allergies mostly involve stable food proteins that cause gastrointestinal disorders including nausea, vomiting, gastric retention, intestinal hyper-motility, abdominal pain due to colonic spasm and diarrhoea. These symptoms rarely occur in isolation and are often accompanied by allergic symptoms in other organs (skin, nose, lungs and eyes) (Asero et al., 2007). Skin symptoms, such as urticaria, are the most common skin disorders in adult patients with food allergy, including cereal allergy. Proteomic techniques are under development for the further identification and characterization of allergens (Uvackova et al., 2013). The resulting data are helpful for the biotechnological production of recombinant pure allergens which may, on one hand, overcome the limitations of natural extracts, but on the other hand lack the effects of the accompanying food matrix.

The way an antigen is presented to the immune system determines its potential allergenicity. This is especially relevant in food allergy. Processing, digestion and the food matrix largely determine the presentation of the food allergen to the immune system of the entire digestive tract. These factors can modify the original form and presentation of the protein and may mask the real characteristics that make the protein an allergen. This is the protein/food side of the allergy coin. The other side is the allergic individual: what factors dispose an individual to first become sensitized and then to become allergic? Genetic predisposition, gender, and age-related physiology, the immune status at the time or season of exposure to allergens, the status of the composition of the (gut) micro-biota, disease history, medication history (including vaccinations and antibiotics used), geography-related and social-economic status-related lifestyle factors and dietary habits all play a role in the sensitization to an allergen, as well as in the clinical presentation after repeated contact with the allergen.

IgE-mediated allergies generally show an immediate response and the offending sources can often be identified relatively easily using panels of allergens in skin-prick tests. This diagnosis is more difficult in intolerances where symptoms have a chronic character and symptoms may be diverse.

\subsection{Intolerances}

Cereal-related intolerances include $\mathrm{CD}$ and wheat/gluten sensitivity. Diagnostic criteria for CD are (1) typical symptoms such as chronic diarrhoea and growth retardation in children, and weight loss and iron deficiency anaemia in adults, concomitant with (2) positive serum coeliac disease IgA class auto-antibodies at high titre (IgA class TTG and EMA in IgA-sufficient, and IgG class TTG and EMA in IgA-deficient subjects; presence of IgG class antideamidated gliadin peptide adds evidence to the diagnosis). Further evidence is (3) the HLA DQ2 or DQ8 genotype. In the small intestine (jejunum), (4) villous atrophy, crypt hypertrophy and the increased intra-epithelial lymphocyte count as measured from biopsies have long been the gold standard for diagnosis. Finally, (5) a positive response to a gluten-free diet is a diagnostic marker. Family history also contributes to the diagnosis. The diagnosis is considered positive when 4 out of 5 of the criteria have been met (or 3 out of 4 if HLA genotyping is not used). Small intestinal biopsy, which is especially burdensome in young children with growth retardation, can now be omitted when high-titre IgA class anti-TTG and EMA antibodies are found ( $>10$ times the upper limit of normal) (Catassi and Fasano, 2010; Husby et al., 2012). Gluten sensitivity exists beyond CD (Biesiekierski et al., 2011; Carroccio et al., 2012) although currently no biological markers are available. The wheat/ gluten elimination diet is presently the only diagnostic tool.

The chronic character of $\mathrm{CD}$ and the wide variety of symptoms, often beyond the spectrum described above, may result in wrong diagnoses (and, as a result, wrong treatments). Current estimates, based on epidemiological data and medical practice, suggest that only a minority ( $\sim 10 \%$ in The Netherlands; Stichting Voedselallergie, website communication) of $\mathrm{CD}$ patients have been properly diagnosed. Many undiagnosed individuals accept a chronic state of ill health as normal, but maintain or worsen their ill health status by continued gluten consumption (Mearin et al., 2005). This is the major societal issue related to CD: how to treat this undiagnosed majority. Mass screening has been proposed (Mearin et al., 2005) while other strategies include various routes of prevention and treatment. This first requires detection of the relevant proteins involved.

\section{Detection of the responsible proteins}

\subsection{Allergens}

Based on IgE from patients' sera, a large number of sensitizing and allergenic wheat proteins have been identified. The most harmful cereal allergens are LTP, $\omega-5$ gliadin and ATIs. These allergens can be involved in different allergy types (Table 1 ). Testing of IgE reactivity in patients with different clinical profiles of wheat allergy (food, WDEIA, bakers' asthma) to salt-soluble and saltinsoluble protein fractions from wheat flour revealed a wide heterogeneity among recognized allergens in groups with different clinical profiles as well as within each group. However, the saltsoluble proteins are mainly associated with bakers' asthma, and prolamins with WDEIA, whereas both protein fractions react to IgE from food-allergic patients (Salcedo et al., 2011). This heterogeneity limits diagnosis and the identification of the specific proteins and their exact epitopes.

Regarding allergy to deamidated gluten, a consensus epitope was found on native $\gamma$ - and $\omega-2$ gliadins (QPQQPFPQ) which is repeated several times in these proteins. Deamidation of the gliadins or peptides to give QPEEPFPE resulted in increased IgE recognition. Allergy to deamidated gluten is considered to be separate from allergy to other wheat proteins. The potential for severe symptoms excludes food challenge tests for diagnosis (Denery-Papini et al., 2012). On the other hand, this allergy is very rare: in France only 15 patients have been diagnosed. Furthermore, deamidated gluten can sensitize mice much more efficiently than natural gliadin. This mouse model of allergy to deamidated gliadin revealed an IgE reactivity pattern against purified gliadins which 
was very similar to that of deamidated gluten-allergic patients (Gourbeyre et al., 2012). Remarkably, these data suggest that deamidation plays a role in the increasing occurrence of allergy to gliadins, in the same way as deamidation increases peptide recognition and binding by $\mathrm{CD} 4+\mathrm{T}$ cells in $\mathrm{CD}$.

\subsection{Intoleragenic proteins}

\subsubsection{The factors determining $C D$ toxicity}

CD is caused by prolamins: gliadins and glutenins from wheat and related proteins from barley and rye. Wheat gluten is a complex mixture of several protein classes representing together about $80 \%$ of the total protein content of the grain. The amounts of prolamins (gliadins) and glutenins are broadly similar (around 50\% for each) among the different wheat species. Table 2 gives an overview of the major protein characteristics of the gluten protein classes. Each class represents a protein family that can be extensive in number and coded by many genes, as for the $\alpha$-gliadins, or small, as for the high molecular weight (HMW) glutenin subunits (Table 3). Specific fragments of these proteins (called epitopes) are involved in the development of $\mathrm{CD}$. Such epitopes can be present in all the gliadins and glutenins of wheat (and similar proteins in barley and rye) and occur in proline- and glutamine-rich protein parts that are resistant to digestion (Bethune and Khosla, 2008). CD epitopes are peptide sequences of nine amino acids. Peptides of this length fit in the HLADQ receptor of the antigen presenting cell and can be recognized by epitope-specific $T$ cells that in turn become activated and start producing cytokines that ultimately can result in inflammation and atrophy of the villi in the small intestine leading to problems with food uptake and further symptoms. The most severe and immunodominant epitopes for $\mathrm{CD}$ are present in the gliadin fraction (Dørum et al., 2009; Tye-Din et al., 2010). In 2012, a list of welldefined CD epitopes (twenty-four HLA-DQ2 restricted epitopes and seven HLA-DQ8 restricted epitopes) was agreed internationally (Sollid et al., 2012). In this list, epitopes from $\alpha$-gliadins and $\gamma$-gliadins are dominating, with six and eleven representatives, respectively. Furthermore, two $\omega$-gliadin epitopes, three LMW-glutenin, and two HMW-glutenin epitopes (only DQ8-restricted) are listed. It is well-established that over $90 \%$ of CD patients are HLA-DQ2 positive while the remainder is usually HLA-DQ8 positive (Koning, 2008). This suggests a minor role of HLA-DQ8 epitopes in the development of CD (Koning, 2012). In addition, when defining an epitope, it is important to assess and categorize this epitope in the context of the HLA molecules that are expressed by the T cell donor. Patients generally express an individual-specific profile of $\mathrm{T}$ cells with epitope-specific sensitivity (Vader et al., 2002; Camarca et al.,
Table 3

Estimated gluten gene copy numbers per gluten type in a haploid genome.

\begin{tabular}{|c|c|}
\hline$\alpha$-gliadins & $\begin{array}{l}\text { Up to } 150 \text { (with } 50 \% \text { pseudogenes) Anderson and } \\
\text { Greene, } 1997\end{array}$ \\
\hline$\gamma$-gliadins & 17-39 Rafalski, 1986 \\
\hline$\omega$-gliadins & 15-18 Sabelli and Shewry, 1991 \\
\hline LMW glutenins & 30-40 Cassidy et al., 1998 \\
\hline HMW glutenins & 2 (1 x-type; 1 y-type) Shewry and Halford, 2002 \\
\hline
\end{tabular}

2009; Sollid et al., 2012). Several steps occur between ingestion and inflammation, forming a reaction cascade in which at least four well-defined factors are the key players.

Firstly, the incomplete digestion of gluten proteins in the gastrointestinal tract. After ingestion, the gastro-intestinal proteases begin to digest the proteins, but gluten proteins are incompletely digested by such enzymes because of their high contents of proline and glutamine residues. Cleavage adjacent to proline is highly disfavoured for most proteases, and glutamine is not a preferred amino acid for any of the proteases in the gut (pepsin, trypsin, chymotrypsin, carboxypeptidases, elastases and brush-border membrane enzymes). In addition, the proteolytic resistance of gluten is enhanced by intra-chain (in the case of gliadins) and inter-chain (especially in glutenins) disulphide bonds that make these molecules poorly water-soluble with low-proteolytically susceptibility (Bethune and Khosla, 2008). It has been hypothesized that gliadins are hardly broken down at all and remain immunologically inactive in healthy individuals, but that $C D$ patients might harbour a CDspecific micro-flora in their small intestine producing gliadinases of bacterial origin that would degrade the gliadins. In this model, the bacterial degradation would lead to $\mathrm{CD}$ in predisposed individuals (Bernardo et al., 2009). A recent discovery appears to contradict this hypothesis. Zamakhchari et al. (2011) and Fernandez-Feo et al. (2013) characterized the oral micro-biome as a rich source of gluten-degrading (including the proteolysis-resistant immunogenic domains) micro-organisms, many of which are selectable and cultivable. But a possible difference in presence or activity of these bacterial enzymes in the saliva of $C D$ versus non-CD individuals was not mentioned, nor the gluten-degradation capacity of this flora demonstrated in vivo, which needs to be established. Nevertheless, the data suggest that the gluten-degrading enzymes from these bacteria might be useful as pharmaceutical drugs or dietary supplements (Zamakhchari et al., 2011; Fernandez-Feo et al., 2013).

Secondly, the low degradability of gluten results in the formation of stable bioactive peptides that have sufficient length to provoke immune responses. Clear examples are a 33-mer and a related 17 -mer $\alpha$-gliadin-derived peptide, which contain multiple epitopes. In two studies, these gluten fragments were recognized

Table 2

Summary of types and characteristics of wheat gluten proteins (adapted from Shewry and Halford (2002)).

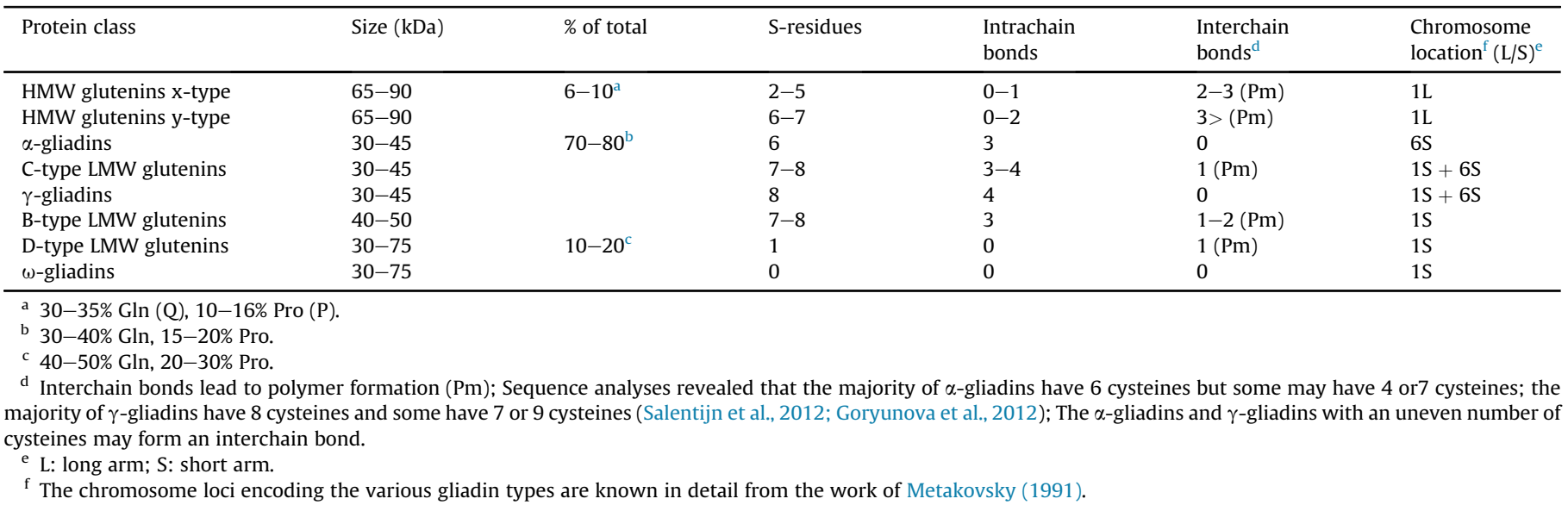


by $\mathrm{T}$ cells from about $50 \%$ of the patients (Vader et al., 2002; Camarca et al., 2009). Another fragment is a 26 -mer $\gamma$-gliadinderived peptide.

Thirdly, before recognition by the T cells, most gluten fragments first need to be deamidated in the lamina propria of the intestine (i.e. the tissue on the body-side of the intestine) by the enzyme tissue transglutaminase (tTG or TG2), which converts glutamine (Q) into glutamic acid (E). This change considerably increases the binding capacity by the HLA-DQ receptor of the antigen presenting cells and the recognition by the $T$ cells, thus making the epitope effective, and in the fourth step, making the T cells proliferate and inflammatory.

Recently, an $\omega$-gliadin-derived peptide was found that is recognized by most $\mathrm{T}$ cells and may be the canonical dominant $\mathrm{T}$ cell-stimulatory peptide in HLA-DQ2-associated CD. Some T cells, especially those specific for the $\omega$-gliadin-derived peptide PFPQPEQPFPW (containing two nine-amino-acid-long overlapping and E-substituted epitopes PFPQPEQPF and PQPEQPFPW), are highly redundant in peptide recognition. This might be due to degenerate recognition or to cross-reactivity as a result of close sequence homologies of reactive peptides (Tye-Din et al., 2010). Furthermore, in addition to the four factors described above, retinoic acid, a metabolite of vitamin $\mathrm{A}$, has been shown in a mouse model to act as an adjuvant that strongly promotes the inflammatory response to gluten (DePaolo et al., 2011).

\subsubsection{Measuring $C D$ toxicity}

The identification and quantification of the CD-immunogenicity (number and clinical impact of various epitopes) of an individual wheat variety, is essential to the development of strategies towards the reduction of $\mathrm{CD}$ as this information will enable the comparison and selection for low- or non-CD toxicity. Hexaploid and tetraploid wheats are self-pollinators, resulting in highly homozygous varieties. Modern varieties are also generally highly uniform. However, old varieties and especially landraces in gene banks are often composed of multiple genotypes, sometimes even mixtures of tetra- and hexaploid seeds (Salentijn et al., 2009). Therefore, gene bank accessions need to be carefully pre-screened for ploidy level and tested on a single-seed basis to select individual lines with reduced $\mathrm{CD}$-immunogenicity. Analysis of $\mathrm{CD}$-immunogenic potential further requires the availability of reliable technical 'tools' based on knowledge of the various aetiology-related factors described above. Most of the tools listed below are available, but all still have serious limitations, which we will discuss.

- A set of epitope-specific monoclonal antibodies to identify the presence (and approximate amount) of specific epitopes

- Patient biopsy-derived epitope-specific T cell clones or induced polyclonal gluten-specific T cells in peripheral blood to verify the immunogenicity of (deamidated) gluten extracts

- Sequence data of CD epitopes in gluten genes present in individual varieties and of $C D$ epitope variants, according to the genome (A, B, D) on which the genes reside

- Expression data for gluten genes in developing seeds from the various genomes in a given line

- Epitope-directed proteomic mass spectrometric analysis of seed proteins

- Volunteer patients for in vivo and epidemiological studies as ultimate proof.

Monoclonal antibodies (mAbs). Sequences that are recognized by mAbs are generally shorter (mostly four to six amino acids) than the nine amino acid-long sequences that are recognized by $\mathrm{T}$ cells. In addition, such mAbs may be insensitive to amino acid substitutions that may abolish $\mathrm{T}$ cell binding, and thus completely destroy the toxic properties of the epitope (Mitea et al., 2010). These factors might lead to overestimation of the amount of $\mathrm{T}$ cell epitopes and inaccurate data on the level of CD toxicity. Before the application of mAbs, an adequate and reliable extraction protocol for these gluten proteins is required. Such a protocol is available (Van den Broeck et al., 2009a,b). Notwithstanding these caveats, commercial mAbs are available in test kits for the detection and quantification of total gluten content in foods, most notably establishing whether or not food is 'gluten-free' (i.e. contains less than 20 ppm gluten). The R5 antibody recognizes an overall motif of $\mathrm{Q}(\mathrm{P})-\mathrm{Q}(\mathrm{P}, \mathrm{L})-\mathrm{Q}(\mathrm{L})-\mathrm{PF} / \mathrm{YP}($ Osman et al., 2001), while the G12 antibody recognizes QPQLPY, QPQQPY and QPQLPF (Morón et al., 2008). Thus, these $\mathrm{mAbs}$ recognise gliadins, not CD epitopes. Results obtained using these mAbs are broadly correlated with the level of $C D$ toxicity because $\mathrm{CD}$ epitopes occur widely in gliadins from wheat and related prolamins from barley and rye. This correlation between the antibody signal and a $\mathrm{T}$ cell response should not be extrapolated to other crops such as oats (Londono et al., 2013, 2014), and it will be invalid once CD-safe varieties or varieties with low levels of $\mathrm{CD}$ epitopes have been developed (see below).

$T$ cells. $T$ cells can be isolated and cloned from patient biopsies. Individual T cell clones (TCC) need first to be tested for epitope specificity. Extracts from cereal seeds should be prepared according to the growth requirements of the T cells, as well as to ensure the presence of all relevant gluten proteins to be tested. Both aspects make T cell tests laborious. Because of the high epitope specificity of each clone, a set of specific TCCs is required to be able to assess the presence of all epitopes in a cereal seed. The outcome is a predominantly qualitative assessment. Suligoj et al. (2013) evaluated the safety of ancient wheat varieties in $\mathrm{CD}$. They observed heterogeneous responses of the TCCs from individual patients to these varieties and concluded that any wheat variety that is suggested to be low in $\mathrm{CD}$ toxicity needs to be tested in multiple $C D$ patients using TCCs because detecting $C D$ toxic epitopes with single gluten-specific mAbs or epitope-specific TCCs will not fully reflect the toxicity of a wheat variety for the overall population of $\mathrm{CD}$ patients. Alternatively, blood samples can be taken from challenged CD individuals. These will contain all or most of the $T$ cells reflecting the patient-characteristic gluten epitope specificities (Camarca et al., 2009) (Tye-Din et al., 2010).

Genomic analysis. Pyrosequencing was used to study the gluten gene family-specific quantitative transcriptome profile at the mRNA level. Salentijn et al. (2009) detected large differences in the transcript frequencies of $\alpha$-gliadins among various hexaploid and tetraploid wheat varieties. Since the genes from the homoeologous loci on the $A, B$, and $D$ genomes within one variety may differ in the amounts of conserved CD-epitopes, screening for differential expression from the homoeologous gliadin gene loci can be employed for the pre-selection of wheat varieties with very low $C D$ immunogenic potential (Salentijn et al., 2009). Furthermore high throughput sequencing of cDNAs enables the classification of wheat lines according to genetic variation in gliadin transcripts and the screening of plants that are potentially less CD-immunogenic. For this, Salentijn et al. (2013) used mRNAs extracted from developing grains. This implies, however, that the observed gene expression does not necessarily correlate to the amounts of the various proteins in the seed endosperm. Nevertheless, the sequence data can be collected into a reference sequence database that is useful as a reference in further quantitative proteomic analysis of the immunogenic potential of mature grains of selected wheat genotypes.

Proteomics. All barley-based beers contain hordein, the barleyspecific prolamin related to wheat gluten. However, ELISA analyses of beer did not correlate with the contents of hordein peptides determined by mass spectrometry (MS) and total epitope load. This is probably due to the fact that the particular 4-6 amino acid sequences detected by the mAbs in the ELISA vary in occurrence 
among hordeins. This highlights the need for new, sensitive and selective quantitative (MS-based) assays (Tanner et al., 2013a,b) such as RP-HPLC, coupled with UV, FLD (fluorescence detection) or MS/MS detection (Konitzer et al., 2013). Currently, the possibilities of using LC-MS are being developed. This method enables nontargeted label-free comparative analysis of the gluten proteins present in different wheat varieties and species resulting in the identification and semi-quantification of gluten peptides containing CD-epitopes. The untargeted LC-MS analysis further allows the design of a faster and quantitative method for subsequent targeted analysis, using triple quadrupole mass spectrometry (Van den Broeck et al., 2013; MS in preparation).

Volunteers. The ultimate proof of the CD-toxicity of a wheat variety or a processed wheat-containing food product is a patient food challenge. Such tests need a double-blind placebo-controlled challenge under ethically agreed conditions. This test is not quantitative since individual volunteering patients will respond differently. This shortcoming can be circumvented by testing a statistically significant number of participants. However, highly sensitive patients will be reluctant to participate in such test panels because of symptom severity. Such tests are laborious and expensive, but necessary as ultimate proof to assess the safety of a food product for diagnosed $\mathrm{CD}$ patients on a gluten-free diet.

Reference material. The Working Group on Prolamin Analysis and Toxicity (PWG) offers a gliadin reference material for scientific research and industrial applications (Peter.Koehler@tum.de). The isolation and characterization of this PWG gliadin has been described in detail (Van Eckert et al., 2006). Briefly, gliadin was extracted from a mixture of 28 European wheat cultivars. Albumins and globulins were removed by extraction using $0.4 \mathrm{M} \mathrm{NaCl}$ and gliadins were extracted with $60 \%(\mathrm{v} / \mathrm{v})$ ethanol. The gliadin extracts were concentrated, desalted by ultrafiltration, freeze-dried, and homogenized. The residual material after lyophilization is referred to as PWG gliadin. Detailed specifications are given on the website of the Working Group on Prolamin Analysis and Toxicity (http://wgpat.com). More recently, a modified two step total gluten extraction protocol has been developed based on the different solubility characteristics of the gliadin and glutenin fractions, enabling quantification of the 'epitope load' for patients using ELISA (e.g. RIDASCREEN ${ }^{\circledR}$ ) or in LC-MS analysis (Van den Broeck et al., 2009a, 2013).

\section{Routes to prevention}

\subsection{Prevention types}

Three levels of prevention can be applied to alleviate symptom development in allergies and intolerances (adapted from the European Allergy White Paper, UCB, 1997, with additions; Gilissen et al., 2006, 2013b):

- Primary prevention addresses in particular symptom-free children who are at risk. Smoking during pregnancy is a high risk factor that should be avoided, as is exposure of the new-born to tobacco smoke. Breast-feeding is recommended (Ivarsson et al., 2002; Chertok, 2007). Sensitization to potent food allergens (eg. wheat bread) can be reduced by avoidance during the first four months of life. Antibiotics should be applied with caution as bacterial infections during childhood may naturally increase the robustness of the developing immune system and strongly limit the development of allergies. Foods that may stimulate the robustness of the immune system, such as oats which contain specific $\beta$-glucans, may help prevention (Van der Meer et al., 2012; Volman et al., 2008).

- Secondary prevention focuses on sensitized individuals in their social context. Symptom development can be prevented by avoidance of the offending allergens in the environment and food. Allergen labelling on packaged foods is currently legally obligatory in Europe. However, 'may contain' labelling may safeguard the producer rather than consumer interest. Due to growing awareness in the food industry, and interest from consumers, the market for 'free from' food products is growing rapidly, especially the 'free from gluten' market.

- Tertiary prevention includes non-dietary therapeutic (medical) treatment of (chronic) symptoms in diagnosed individuals. In the case of $\mathrm{CD}$, the proven treatment is a strict life-long gluten-free diet. Other treatments being developed include supplementation with gliadinase or gluten-degrading human oral micro-organisms or enzymes isolated from such organisms (Fernandez-Feo et al., 2013), the use of specific mAbs (such as anti-CD3, anti-CD20 and anti-IL15) or of HLA blockers and TG2 inhibitors, or the induction of gluten-tolerance via epitope-based vaccination. These and other therapies have been discussed and evaluated by Osorio et al. (2012). These medical strategies, however, need first to be proven safe and as efficacious as a gluten-free diet (Lindfors et al., 2012), and preferably to be cheaper, easier and less burdensome. Some of these strategies have already been found to be adverse, e.g. the anti-CD3-induced toxic cytokine syndrome (Lindfors et al., 2012). Increasing attention is also being paid to complementary and alternative medical treatment (at the level of prevention, care and cure, and their potential to modulate the effects of allergic diseases) (Li, 2012).

\subsection{Allergy/Intolerance knowledge framework}

The genetic predisposition of an individual with its specific lifestyle related physiological and immunological status in its specific environment determines the response to an allergen in the specific food or environmental matrix. This reflects the multifactorial nature of allergy and intolerance. As a consequence, the prevention of allergy and intolerance recognizes a multifactorial and multi- and interdisciplinary approach, with specific attention paid to each individual allergen and its source. One element that we consider requires more attention is the possibility to prevent disease, and to develop prevention strategies at the pre-medical stage (primary and secondary prevention strategies). Such strategies benefit from a knowledge framework in which data are collected and analysed at different levels for further societal implementation. Such levels may include (Gilissen et al., 2012a):

- Fundamental research. Data need to be collected and integrated to create an understanding of the phenomenon of allergy/ intolerance with regard to the aetiology of the disease (sensitisation and symptom development) and of the allergenicity- or tolerance-breaking capacity of a given environment or food source (i.e. which factors make the source allergenic/intolerable and what makes a specific protein from that source an allergen/ intoleragenic compound?) This should include the multidisciplinary integration of medical and food sciences.

- Designing research. Based on the fundamental knowledge, specific and efficient tools can be developed for improved diagnosis of patients and to adapt life-style in such a way that allergens and intoleragenic compounds can be avoided; this knowledge also allows better characterization of allergenic sources aiming at designing hypoallergenic products and environments.

- Development of practical prevention strategies. Based on the tools that are designed and the identified prerequisites and stakeholders, practical and straightforward strategies can now be developed for prevention and management of allergy/intolerance but what actions are needed from what stakeholder? 
- Implementation. This requires the active and coordinated contributions of various stakeholders, e.g. to make an operational allergen- (gluten-) free production chain, to distribute consumer-friendly tools (such as internet apps) for easy product scanning for allergens in supermarkets, and to improve plans for large-scale growing of allergen- or gluten-safe crops.

- Dissemination. Education, communication and exchange of information among and between stakeholders further facilitates and complements the knowledge framework to establish a solid, flexible and sustainable infrastructure in society.

For any given type of allergy or allergenic source, these levels can be integrated into a matrix to better identify gaps of knowledge and to facilitate the various actions to be taken for prevention, specifically or in general. Such a matrix will include medical and natural sciences on the one hand, and social sciences, governmental actions and responsibilities, and commercial activities and production on the other hand. Application of the matrix approach will elucidate the multidisciplinary nature of allergy and intolerances, and their prevention and management, and opens ways for cooperation in interdisciplinary settings, from local initiatives (crop cultivation systems; production of easy achievable and reliable information on hypoallergenic and gluten-safe products) to the establishment of large national and international public-private partnerships (e.g. HealthGrain Forum; Working Group on Prolamin Analysis and Toxicity; Coeliac Disease Consortium; The Dutch Oat Chain).

\subsection{Potential and current prevention activities}

Cereal proteins can come into contact with individuals through ingestion, inhalation and through contact with the skin. Cerealrelated allergies and intolerances present a diversity of clinical symptoms that are not necessarily presented separately and can be individual-specific. This hinders identification of the source and the nature of the allergen/intoleragen, the aetiology of the symptoms, and the development of appropriate prevention strategies. Such strategies can be directed at the undiagnosed (to reduce the incidence) or diagnosed (to reduce the occurrence and severity of symptoms) levels, and at the individual and the (sub) population levels and require application of the 'allergy knowledge framework' approach to the identify the knowledge gaps (Table 4).

\subsubsection{Prevention of cereal allergies}

Of all forms of wheat allergy, occupational bakers' asthma has the highest direct economic impact, but strategies to reduce the impact remain limited by gaps in our knowledge. According to Salcedo et al. (2011) these include the wide heterogeneity in sensitization patterns among patients regarding the different

Table 4

Levels of approach of the Allergy/Intolerance knowledge framework.

\begin{tabular}{lll}
\hline & Individual & Population \\
\hline Undiagnosed & $\begin{array}{l}\text { Identification of individuals } \\
\text { at risk (primary prevention) }\end{array}$ & $\begin{array}{l}\text { Reducing application of major } \\
\text { allergens/intoleragenic } \\
\text { compounds (especially wheat, } \\
\text { and gluten) in foods (including } \\
\text { those in which they did not use } \\
\text { to occur (similar approach as } \\
\text { reduction of fat, carbohydrate, } \\
\end{array}$ \\
& & $\begin{array}{l}\text { salt); adaptations of social } \\
\text { environments (e.g. school, } \\
\text { sporting facilities) }\end{array}$ \\
& & $\begin{array}{l}\text { Facilitation of availability of } \\
\text { allergen-free foods and } \\
\text { environments }\end{array}$ \\
& Allergen-free products; \\
& adaptation of in-house and \\
& working (bakery) conditions &
\end{tabular}

proteins that can be involved, the lack of clear markers of clinical symptoms and of purified (natural and recombinant) allergens for diagnostic tests (including lack of knowledge on the glycosylation of specific potential allergens such as amylase inhibitors and peroxidases), the relatively low numbers of volunteer patients that can be included in tests, the route of sensitization, and the lack of conclusive results on cross-reactivity with other cereal flours (rye, barley), pollen (from grasses, birch, Artemisia) and plant foods (e.g Rosaceae fruits). The current incidence of bakers' asthma among young bakers ranges from 0.3 to 2.4 cases per 1000 person-years and is increasing among supermarket bakery workers (Salcedo et al., 2011 and references therein). Strategies for the prevention of bakers' asthma should therefore not be based on modifying or eliminating the allergenic protein sources in the cereal (flour), but rather focus on adaptation and improvement of the occupational working conditions, including adjusting air flows and protection from inhalation.

In the case of cereal food allergy, the range of proteins responsible for sensitization and symptom development is wide (Battais et al., 2008). Quantitative and qualitative differences in allergens have been observed among wheat varieties and species, (e.g. in their IgE binding). Bread wheat varieties that lack the Gli-B1 locus for $\omega$-gliadins did not cause certain severe symptoms. Also Triticum spelta (spelt), Triticum turgidum (farro) and Triticum monococcum (einkorn) showed differences in allergen contents. The in vitro and in vivo reactivities of patients with wheat food allergy-related eczema were lower with diploid T. monococcum (Denery-Papini et al., 2007, 2009). Currently, attention to other wheat species is growing as demand is increasing. Einkorn and spelt wheat are increasingly mentioned as less burdensome to allergic individuals than common bread wheat. However, more sound scientific data to support this 'hypoallergenic' characteristic are needed (see also below under Tolerances). When patients are diagnosed, a glutenfree (in fact also wheat-free) diet is still the option of choice for prevention of symptoms.

Because of the thermo-stability of the major cereal allergens (nsLTP, ATI, and $\omega-5$ gliadin), processing (heating) apparently does not reduce their allergenicity and is not a viable strategy for prevention of allergy.

\subsubsection{Prevention of intolerances to cereals}

5.3.2.1. In search for low CD-toxic wheat varieties. Selection of accessions from gene banks. Many thousands of wheat accessions are maintained in gene banks worldwide (including the Centre of Genetic Resources, the Netherlands (CGN) in Wageningen). These include modern and old hexaploid and tetraploid varieties (originating from selection and breeding), landraces, cultivated and wild species, and diploid wild species that are related to the ancestors of cultivated wheat. Synthetic hexaploids have also been produced in which genetic variation in the D genome has been introgressed from wild Aegilops tauschii. These collections of natural and synthetic wheats form a useful source for analysis of the relationships between individual gluten genes and proteins and CD toxicity, and for identifying wheat lines with reduced CD toxicity.

It has been shown that the occurrence of epitopes for $C D$ varies among gliadin genes, between homoeologous loci, and between wheat varieties and species. For example, the $\alpha$-gliadin sequences from the A, B and D genomes appear to form distinct groups that have a non-random distribution of $T$ cell epitopes with the $D$ genome contributing most to $\mathrm{CD}$ immunogenicity and the $\mathrm{B}$ genome the least (Mitea et al., 2010; Van Herpen et al., 2006; Molberg et al., 2005; Spaneij-Dekking et al., 2005). This situation appears to be similar for the $\gamma$-gliadins (Salentijn et al., 2012), as the highest number of $C D$ epitopes was found in the $\gamma$-gliadins from the $\mathrm{D}$ genome. For $\omega$-gliadins it is not clear because of the lack of 
sequence information on this type of gliadin; the involvement of $\omega$ gliadins in $C D$ toxicity has been only recognized recently in the context of a high degree of cross-reactivity with rye and barley (Tye-Din et al., 2010).

The occurrence and level of $\mathrm{CD}$ epitopes has been compared between large sets of modern and old hexaploid wheat varieties, land race accessions, and tetraploid accessions. In modern varieties, genetic diversity was limited and they showed overall high total binding to mAbs specific for Glia- $\alpha 1$ [PFPQPQLPY] and Glia- $\alpha 3$ [FRPQQPYPQ] epitopes. Remarkably, the modern varieties demonstrated an increased amount of Glia- $\alpha 1$ epitopes and a reduced amount of Glia- $\alpha 3$ epitopes. This may explain why coeliac patients respond more violently to Glia- $\alpha 1$ epitopes than to Glia- $\alpha 3$ epitopes (Vader et al., 2002; Camarca et al., 2009). In addition, this may be the reason for a higher prevalence of $C D$, because the level of the immuno-dominant epitope Glia- $\alpha 1$ seems to have increased as a result from wheat breeding during the last decades (Van den Broeck et al., 2010). Furthermore, old hexaploid wheat varieties have been identified with relatively low $m A b$ responses, suggesting a low number of immuno-dominant CD epitopes. Such lines may be useful at reducing levels of $C D$ epitopes as a new quality trait for breeding. In addition, such screening revealed the existence of a tetraploid durum wheat land race with strongly reduced $\mathrm{mAb}$ responses. This land race was a heterogeneous mixture of seeds, from which two single seed-derived lines have been selected and multiplied for further analysis. These lines will be exploited for direct applications in food products, e.g. pasta and pizza (Van den Broeck et al., 2010). Analysis of nine cultivars of farro wheat (T. turgidum) in a test with $T$ cells from four patients revealed negligible proliferation responses comparable to the untreated control, whereas the other varieties showed intermediate to very high responses (Vincentini et al., 2009). For the diploid einkorn (T. monococcum), which is an ancient A genome wheat species with relatively good nutritional characteristics and bread making quality, the variety Monlis was well-tolerated by $\mathrm{CD}$ patients and showed similar absence of $C D$ toxicity-related events as rice, which was used as the control (Zanini et al., 2013). As combinations of gluten genes containing low $\mathrm{CD}$ epitopes are much more easily made by crossing and selection in a diploid species, this is an intriguing finding that needs to be confirmed by studies employing other patients and detection methods.

Deletion lines. A set of hexaploid wheat deletion lines from the variety Chinese Spring (Wheat Genetic \& Genomic Resource Center [WGGRC], Kansas State University, USA, http://www.k-state.edu/ wgrc/Germplasm/Deletions/del_index.html) was used to test the effects of individual loci on reduction of CD toxicity and changes in technological properties. Removal of the $\alpha$-gliadin locus from the short arm of chromosome 6 of the D genome (6DS) (Table 2) resulted in strongly decreased $\mathrm{mAb}$ responses against the Glia- $\alpha 1$ and Glia- $\alpha 3$ epitopes. Concomitantly, a significant loss of technological properties, such as dough mixing properties and dough rheology, was observed. The dough became stiffer and less elastic. In contrast, the deletion of $\omega$-gliadins, $\gamma$-gliadins and low molecular weight (LMW)-glutenin subunits from the short arm of chromosome 1 of the D genome (1DS) (Table 1) apparently removed some epitopes but retained technological properties (Van den Broeck et al., 2009b). To improve or restore dough quality, oat prolamins (avenins) appear to be a good alternative for wheat gliadins and could be added to the flour of certain wheat deletion lines that lack encoding CD-stimulating gliadin proteins (Van den Broeck et al., 2011). These lines may be economically competitive so as to be developed commercially.

Genetic modification. Hexaploid bread wheat contains many different gluten proteins (Table 1), most of which contain CD epitopes. The genes for these proteins are present in blocks that are inherited as single loci (Table 2). It is therefore not possible to develop a CD-safe bread wheat variety through crossing and selection alone. Since glutenins are most important for baking quality, while gliadins contain most of the $\mathrm{CD}$ epitopes, scientists have been exploring ways to mutate gliadins or to delete or to silence their genes. Becker et al. (2012) silenced $\alpha$-gliadins using RNA interference (RNAi), eliminating 20 different storage proteins from the grains. Gil-Humanes et al. (2010) also effectively down-regulated the CD-related gliadin genes in bread wheat by an RNAi approach. T cell tests revealed a 10-100-fold reduction in the amounts of DQ2 and DQ8 epitopes in $\alpha$-gliadins, $\gamma$-gliadins and $\omega$ gliadins. Total gluten extracts of three transgenic wheat lines were unable to elicit T cell responses (Gil-Humanes et al., 2010). Downregulation of the $\gamma$-gliadins only resulted in non-specific increases in other gluten proteins, but had no or little effect on dough strength and on gluten and starch properties (Pistón et al., 2011; Gil-Humanes et al., 2012). These lines have been developed in Spain, which has a less restrictive attitude to genetically modified (GM) crops. Another report describes transcriptional suppression of wheat DEMETER (DME) homoeologous using RNAi. The DME genes encode a 5-methylcytosine DNA glycosidase, which is responsible for the transcriptional de-repression of gliadins and LMW glutenin subunits by active demethylation of their promoters in the wheat endosperm. The transformed plants showed a high degree of suppression in DME gene transcript abundance resulting in over $75 \%$ reduction in the amount of immunogenic prolamins. Such lines may form the basis for the development of wheat varieties compatible for coeliac patients (Wen et al., 2012). Such RNAi wheat lines, where their other agronomic properties, yields and regulatory aspects are acceptable, may become candidates for the production of wheat-based products for 'gluten-free' or 'low-in-gluten' diets. The European attitude towards GM crops is now changing. In the UK, a policy has been initiated at the governmental level to accept GM crops and the UK government now advocates more flexibility with the EU on the advantages of GM, supporting the current advice of the European Food Safety Authority (David Cameron, The Telegraph, 14 June 2013).

Breeding. 'Reduced CD toxicity' (through a combination of selection of germplasm, mutation breeding, and/or genetic modification) will become a global breeders' aim in the near future. Although breeding of bread wheat varieties exclusively through crossing and selection will not produce varieties that are completely safe, selection can consider the allelic blocs or clusters (Metakovsky, 1991) and pyramidize within a line (variety) the blocs carrying the lowest numbers of epitopes. Here, deep mRNA sequencing and proteomics are useful tools for efficient diagnosis of the selected lines regarding quantification of CD toxicity (Salentijn et al., 2013). The application of such new less- or non-CD-toxic wheat varieties in food products will then require the development of separate production chains from field to consumer to avoid contamination with regular high CD-toxic wheat varieties. Such developments, when accepted globally, may have a strong impact on reducing the incidence of gluten-related disorders in the general population.

5.3.2.2. Production of $C D$-safe cereal foods by processing and other technological approaches. People who suffer from CD require a gluten-free diet. Wheat/gluten-free diets generally suffer from limitations especially concerning nutritional value, fibre content, taste and palatability. Several technologies can be applied to reduce the $\mathrm{CD}$ toxicity by processing.

Sourdough fermentation. Sourdough bread-making is a very ancient technology, that may today make a valuable contribution to the production of high-quality bread from various CD-safe cereals (such as sorghum), but also from wheat and rye (Moroni 
et al., 2009). Loponen (2006) examined gluten degradation during sourdough fermentation and suggested that proteolytic food processing technology could be used to manufacture new 'glutenfree' or 'low CD-toxic gluten' wheat-based products. A 60 days administration of a wheat flour-derived product, containing a hydrolysed gluten content below $10 \mathrm{ppm}$ through Lactobacillus sourdough fermentation, appears not to be harmful to CD patients. Hydrolysis was achieved in two steps. Medium sized polypeptides (including the 33-mer $\alpha$-gliadin derived fragment) were obtained from a primary hydrolysis using fungal proteases, and were further degraded by Lactobacillus endo-peptidase activity (Greco et al., 2011). These observations are promising, but it is too early to claim that sourdough is CD-safe. Further research is needed in two directions: (1) what is the potential of sourdough (bread) products in a safe 'gluten-free' diet for individual cases and (2) can large-scale consumption of sourdough products by the whole population (including the potential and non-diagnosed patients) contribute to reduction of the incidence and symptom severity of $\mathrm{CD}$ and ncGS? Economically, this approach may enlarge the current niche market for sourdough products. Interestingly, the prevalence of CD (measured using a single antibody test) in Germany, with a longstanding tradition of sourdough bread consumption, is remarkably low: $0.4 \%$ among women, and $0.2 \%$ in men (Kratzer et al., 2013).

Production of safe gluten proteins. The presence of several major epitopes has been recognized in $\alpha$-gliadins and other gluten proteins, of which the HLA-DQ2-Glia- $\alpha 1$ (PFPQPQLPY), HLA-DQ2-Glia$\alpha 2$ (PQPQLPYPQ), HLA-DQ2-Glia- $\alpha 3$ (FRPQQPYPQ) and HLA-DQ8Glia- $\alpha 1$ (QGSFQPSQQN) are dominant. Would it be possible to 'detoxify' such epitopes? To answer this crucial question, the sequences of over 3000 naturally expressed $\alpha$-gliadins from 11 bread wheat varieties were analysed to determine whether they encode for peptides potentially involved in $C D$. This provided data on the frequency and genome relationships (A, B, or D) of the canonical sequences and their natural variants. All variant peptides have been synthesized and tested for binding to the disease-associated HLADQ2 and HLA-DQ8 molecules and for recognition by patientderived $\alpha$-gliadin specific T cell clones. Several naturally occurring amino acid substitutions were identified for each of the variant peptides that appeared to have no antigenic properties. From these data, Mitea et al. (2010) concluded that the CD toxicity of the four T cell epitopes in $\alpha$-gliadins can be completely eliminated by utilizing naturally occurring amino acid substitutions. This strategy can be extended to all other epitopes in gliadins and glutenins. It is expected that such modified gluten proteins will show no differences in technological properties, thus enabling further steps towards the production of CD-safe gluten proteins for food products. This knowledge can be applied to recombinant production in large-scale fermenters of safe gluten proteins for food industry uses. However, although this may result in the long run in mass production of pure CD-safe gluten, it will never be able to out-compete the worldwide and large-scale production of 'vital gluten' as a by-product from the starch industry. Alternatively, a set of CD-safe gliadin and glutenin protein genes can be introduced recombinantly in otherwise gluten-free crops (such as maize or rice) to considerably improve their technological (bread baking) properties and thus to increase product choice for gluten-intolerant individuals. However, it is first necessary to show that these crops are able to express gluten proteins in effective amounts. In addition, the genetically modified nature of these foods may still remain (in the near future, at least in Europe) a barrier to acceptance. Furthermore, the detection system for gluten-free food would have to be improved to be able to distinguish between gluten proteins with and without CD epitopes.

Reduction of gluten use in foods. Alternatively, the total amount of gluten in food products may be reduced as currently recommended for salt, carbohydrates and fat and adopted by the food industry. The extraction of gluten (so-called 'vital gluten') from starch is a large-scale and low-tech procedure. Vital gluten is increasingly applied as additive in food products for technological improvement. The addition raises the question about the amount of vital gluten that contributes to total gluten consumption. Kasarda (2013) calculated a triple increase in vital gluten consumption since 1977, which may be of interest because this time frame fits with the estimations on the increased prevalence of CD (Rubio-Tapia et al., 2009). Since 2000, gluten production at least doubled, which may have led to further increase in gluten consumption. Notably, whole grain bakery products (e.g. bread) require high amounts of additional vital gluten to maintain high loaf volumes. As the economic margin on gluten protein is low (it is currently among the cheapest proteins world-wide), no technological improvements to extraction are to be expected to occur in the near future. However, it can be suggested that the efficiency of gluten production can be improved by more thorough extraction procedures, retaining functionality and allowing the use of less gluten to achieve the same results in food processing.

Separation. Gliadins and glutenins can be separated almost completely at the lab scale (Gilissen et al., 2012b). At the industrial scale this process is more recalcitrant but extraction of the gliadin and the glutenin fraction can be achieved (Bassi et al., 1997). The glutenin components are more important for processing quality than the gliadin components which can functionally be replaced (by for example avenin from oat; see above, Van den Broeck et al., 2011). As the gliadins contain most of the coeliac-relevant epitopes, separation of the glutenin fraction from the total gluten in an economically and technologically viable way will contribute to produce food products for the overall population, including undiagnosed coeliac and gluten-sensitive individuals, with significantly reduced $C D$ toxicity.

Gluten alternatives. Another novel approach is to develop alternative protein systems for elastic dough making. One such alternative is to use a structured suspension containing whey protein particles. This is based on the hypothesis that a number of gluten characteristics originate from a particle structure present in the gluten network. Early promising results showed changes in a starch mixture from a liquid into a cohesive material with strain hardening (dough) properties (Van Riemsdijk et al., 2011). This research is now being continued to improve the dough-making qualities of oat flour (Londono et al., 2014).

Infant diet. In Sweden, a four-fold increase in the incidence of CD was recorded due to changed infant feeding practices including the use of increased amounts of gluten (Ivarsson et al., 2000). This increase strongly suggests that the total amount of gluten in the diet is a factor in determining incidence and prevalence. Indeed, a change towards the more gradual introduction of glutencontaining foods into the diet of infants while being breast-fed was found to reduce the risk of CD in early childhood and beyond (Ivarsson et al., 2002). This subject is now under further investigation in the framework of PREVENTCD (www.preventcd.com). The conclusion of this study from a systematic review of early infant feeding and the prevention of CD is that it is sensible to avoid both early ( $<4$ months) and late ( $>7$ months) introduction of gluten, and to introduce gluten while the infant is still being breastfed (Szajewska et al., 2012). Furthermore, the UK branch of the ESPGHAN together with Coeliac UK recently published guidelines for the diagnosis and management of $C D$ in children, aiming at simplification and shortening of the diagnostic process and providing didactic stratagems to be of assistance for nongastroenterological pediatricians (Murch et al., 2013).

The gluten-free trend. 'Gluten-free' seems to have become a global trend with a significant annual market growth since 2004 
(Sapone et al., 2012). Starting in the USA, this billion dollar market trend is expected to reach Europe soon and may cause a considerable reduction in overall gluten consumption. As a consequence, the incidence of $\mathrm{CD}$ may decrease. However, there are currently no data on the impact of this trend on the incidence and prevalence of $\mathrm{CD}$, probably because such figures are masked by the rapid growth (in the awareness) of 'gluten sensitivity' as a new 'disease'.

Improvement of the gluten-free diet per se. Some patients have persistent symptoms and villous atrophy despite strict adherence to a gluten-free diet. They are referred to as having "nonresponsive $C D$ ", a subset of which has true refractory $C D$. Some nonresponding $C D$ patients simply react to gluten cross-contamination present in regular gluten-free food products. Most (over 80\%) of these patients improved on a gluten contamination elimination diet (GCED), including plain unflavored brown and white rice, fresh fruits and vegetables, meats, and fish, eggs, dried beans, nuts in the shell, butter, unflavored yoghurt, milk and cheese, oils, vinegar, honey and salt, $100 \%$ pure fruit and vegetable drinks. These patients appeared not to be refractory and were able to return to a traditional gluten-free diet without return of symptoms. This clearly demonstrates that the traditional gluten-free diet still contains amounts of gluten that may prevent some very sensitive patients from recovering (Hollon et al., 2013).

5.3.2.3. Alternative cereals. The gluten intolerance-causing cereals (wheat, rye and barley) all belong to the Triticeae clade of grasses. This is most closely related to the Aveneae, Chlorideae, Oryzeae and Festucaceae clades, to which oats, teff, rice and finger millet (ragi) belong, respectively. More distantly related are the Trypsacineae, Andropogoneae and Paniceae, which include maize, sorghum and millet, respectively. The seeds of all these species contain storage proteins with some similarities to gluten (see above: 2.1. Cereal allergy). All cereals beyond the Triticeae are considered safe for gluten-sensitive individuals. Oats have been for a long time on the list of toxic gluten-containing cereals. However, it appeared that the most serious problem for $\mathrm{CD}$-patients in consuming oat products was the frequent contamination with wheat gluten and gluten containing cereal material which occurs during cultivation, harvest, storage, milling, baking, etc.

There is sound scientific evidence that gluten-intolerant patients can regularly eat amounts of oats without any harm (Pulido et al., 2009; Kaukinen et al., 2013), even though oat avenins can elicit $\mathrm{T}$ cell responses in some rare cases (Arentz-Hansen et al., 2004). Several factors may be involved in the relative CD-safety of oats: (1) although avenins (the oat prolamins) are structurally related to wheat gliadins (most closely to $\omega$-gliadins), only a few gene copies are present; (2) the total amount of avenins in oats is much lower than the total amount of gliadins in wheat; (3) none of the currently known epitopes from wheat, rye and barley occur in oats (Londono et al., 2013); (4) two avenin-specific epitopes exist, but only very few patients react to these. Thus, consumption of oats results in much lower and generally tolerated exposure to antigenic peptides, if any (Tjon et al., 2010). This makes oats a good replacement for wheat, rye and barley, providing an important rich-in-fibre ( $\beta$-glucan) and also otherwise healthy supplement (Jones and Anderson, 2008; Andon and Anderson, 2008) of the patients' daily diet (Peräaho et al., 2004).

In January 2009, EC Regulation 41/2009 on the content and labelling of foods for individuals with CD came into force in Europe. Oat products containing less than $20 \mathrm{ppm}$ gluten are now allowed to be sold as gluten-free in the Netherlands and may carry the official logo of the Dutch Coeliac Disease Patient Society. Countries such as Sweden and Finland have already developed separate gluten-free oat production chains. In the Netherlands, a CD-safe chain extending from the field to the consumer was recently established in cooperation with food industries and the Dutch Coeliac Disease Patient Society. Its first products were marketed in 2011 and several new gluten-free oat-based product types are under development (Gilissen et al., 2012b), one of which is glutenfree oat beer, in cooperation with a consortium of Dutch breweries. Since August 2013, also the USA (www.federalregister.gov) allows oats to be sold as gluten-free, provided any contamination with gluten from wheat, barley and rye is below 20 ppm. This demonstrates that worldwide governments (although Australia and New Zealand might still be reluctant according to their Food Standard Code) recognize that the positive effects of oat consumption by coeliacs outweigh by far the minor potential hazards.

Recently, Kaukinen et al. (2013) further confirmed the safety of oats for $\mathrm{CD}$ patients from a long-term consumption study involving over 100 coeliac volunteers. Oat consumption of $20 \mathrm{~g}$ (range 1$100 \mathrm{~g}$ ) per day for eight years resulted in significantly better mucosal morphology when oats was consumed in higher amounts over a longer period, as compared to the controls that used a gluten-free diet without oat during this period, which is suggested to be the positive effect of oat fibre intake.

\section{Further considerations}

\subsection{Lifestyle, diet and micro-flora}

The high frequency of individuals sensitized to a broad variety of cereal (i.e. wheat) proteins led Zuidmeer et al. (2008) to suggest that wheat (and related cereals) foods have high immunogenic potential, perhaps greater than other foods in general. We hypothesize here that the consumption of wheat positively influences the maturation of the immune system in early childhood and the intestinal microbial community of individuals that are not affected by the 'western lifestyle', but may act negatively on the health of individuals with a genetic predisposition and suffering from the western lifestyle syndrome with disturbed immune and (intestinal) microbial functioning and increased susceptibility to develop chronic inflammatory diseases. Several environmental factors, many of which are microbial, may have led to a decrease in the efficiency of immuno-regulatory mechanisms in humans living in modern urban environments. In such environments, many microbes with which humans have co-evolved as inducers of immuno-regulatory circuits are reduced in occurrence. Integration of research on factors related to gut micro-biota (including foetal programming by maternal microbial exposure, neonatal programming and hygiene), diet and lifestyle, combined with human genetics, can provide the missing immuno-regulatory environmental factor(s) needed to explain the recent increases in immune-related diseases. The manipulation of the gut micro-flora is in its infancy but may have enormous potential for the future in this regard (Rook, 2011, 2012).

\subsection{European organisations on health and disease aspects of cereals}

Because of their direct or indirect activities directed towards the reduction of cereal allergies and intolerances, several international and European organisations working on cereals in relationship to health and disease should be mentioned here:

- EAACI: European Academy of Allergology and Clinical Immunology (www.eaaci.org)

- ESPGHAN: European Society for Paediatric Gastroenterology, Hepatology, and Nutrition

- AOECS: Association of European Coeliac Societies (www.aoecs. org) 
- HealthGrain Forum (including its 'Cereality Europe' initiative) (www.healthgrain.org)

- Working Group on Prolamin Analysis and Toxicity (www.wgpat. com)

- PreventCD (www.preventcoeliacdisease.com)

- Celiac Disease Consortium (The Netherlands) (www.celiacdisease-consortium.nl)

Further research initiatives may be appropriate for support from the Horizon 2020 framework in the European Technology Platform "Food for Life". Its strategic research and innovation agenda (20122020 and beyond) includes 'The gluten challenge: a public health issue of growing significance (Section B, Project 22; http://etp.ciaa. eu, p54) with a focus on the reduction of (coeliac) toxicity in regular wheat- and gluten-containing foods, and on the production of guaranteed safe foods particularly for individuals that are already diagnosed with CD and ncWS and have to follow a life-long glutenfree diet (Gilissen et al., 2012b).

\section{Concluding remarks}

We have discussed strategies for reducing the incidence of cereal allergies and intolerances. Cereal allergies are rare but responses to the offending foods can be rapid and consumption should be avoided.

In the case of cereal intolerances, the symptoms are chronic and diverse, and many patients are undiagnosed or misdiagnosed because the patient is unaware of the causal factor (gluten) or because the clinician is ignorant of the illness and its symptoms. Several strategies have been proposed to reduce the incidence and prevalence. One strategy is based on the assumption that any reduction in the overall amount of 'toxic' gluten in food products will help to decrease sensitivity and associated symptom severity. The processing quality of gluten depends mainly on the glutenin fraction, whereas the gliadin fraction contributes most to toxicity. This opens routes for 'detoxification'. The reduction or absence of the toxic gliadins while maintaining the glutenins can now become a new breeding aim. Wheat lines have been selected that show low responses towards various gluten epitope-specific mAbs and have proved to be low in immunogenic gluten epitopes when analysed by mass spectrometry. This research demonstrated high variation in toxicity, especially among old varieties which may serve as starting material in breeding programmes for low CD epitopecontaining wheat. Approaches such as partial chromosome deletion and re-synthesis of new hexaploids may be required to develop CD-safe wheats in combination with gene silencing through RNAi technology. Avenins (prolamin proteins from oats) appear to be good and safe replacements for gliadins.

The other strategy focuses on individuals with diagnosed $\mathrm{CD}$ for whom food processing (i.e. hydrolysis of gluten through sourdough fermentation), large-scale recombinant expression of sets of 'detoxified' gliadins and glutenins in safe food crops, and the development of alternative safe cereals, especially oats, may be appropriate. However, the nutritional quality and the safety of the gluten-free diet should be guaranteed.

Multidisciplinary and interdisciplinary approaches are required to execute these strategies, posing new challenges and responsibilities for wheat breeders, food industries, research organizations and governments to better balance wheat (cereal) and gluten applications with food safety. We are aware that these are the 'nearby' and 'ad hoc' approaches. Improving our understanding of the interaction between the three major pillars: (1) food (eating pattern and life style), (2) human genetics and physiology, and (3) intestinal micro-flora, is a further and deeper approach that will ultimately deliver applications which are more effective to sustainably reduce the incidence and prevalence of immunerelated diseases, including cereal allergy and intolerance.

\section{Acknowledgements}

This research was funded by the Coeliac Disease Consortium, an Innovative Cluster approved by the Netherlands Genomics Initiative and partially funded by the Dutch Government (BSIK03009), by the Ministry of Economic Affairs (KB15-001-007) and by the EFRO project 'Nieuwe detectiemethoden voor coeliakie en coeliakieinducerende gluten in voeding' (2011-018974).

\section{References}

Anderson, O.D., Greene, F.C., 1997. The $\alpha$-gliadin gene family. II. DNA and protein sequence variation, subfamily structure, and origins of pseudogenes. Theor: Appl. Genet. 95, 59-65.

Andon, M.B., Anderson, J.W., 2008. The oatmeal-cholesterol connection: 10 years later. Am. J. Lifestyle Med. 2, 51-57.

Antebi, Y.E., Reich-Zeliger, S., Hart, Y., Mayo, A., Eizenberg, I., Rimer, J., Putheti, P., Pe'er, D., Friedman, N., 2013. Mapping differentiation under mixed culture conditions reveal a tunable continuum of T cell fates. PLoS Biol. 11, e1001616. http://dx.doi.org/10.1371/journal.pbio.1001616.

Arendt, E.K., Moroni, A., Zannini, E., 2011. Medical nutrition therapy: use of sourdough lactic acid bacteria as a cell factory for delivering functional biomolecules and food ingredients in gluten free bread. Microb. Cell Fact. 10 (Suppl. 1), S15.

Arentz-Hansen, H., Fleckenstein, B., Molberg, O., Scott, H., Koning, F., Jung, G. Roepstorff, P., Lundin, K.E.A., Sollid, L.M., 2004. The molecular basis for oat intolerance in patients with celiac disease. Plos Med. 1, 84-92.

Asero, R., Mistrello, G., Roncarolo, D., Amato, S., 2007. Detection of some safe plantderived foods for LTP-allergic patients. Int. Arch. Allergy Immunol. 144 (1), 57 63.

Atchison, J., Head, L., Gates, A., 2010. Wheat as food, wheat as industrial substance comparative geographies of transformation and mobility. Geoforum 41, 236246.

Aziz, I., Hadjivassiliou, M., Sanders, D.S., 2012. Does gluten sensitivity in the absence of coeliac disease exist? BMJ 345, e7907.

Barera, G., Bonfanti, R., Viscardi, M., Bazzigaluppi, E., Calori, G., Meschi, F., Bianchi, C., Chiumello, G., 2002. Occurrence of celiac disease after onset of type 1 diabetes: a 6-year prospective longitudinal study. Pediatrics 109 (5), 833-838.

Bassi, S., Maningat, C.C., Chinnaswamy, R., Gray, D.R., 1997. Alcohol-free Wet Extraction of Gluten Dough into Gliadin and Glutenin. United States Patent, $\mathrm{Nr}$ $5,610,277$.

Battais, F., Richard, C., Jacquenet, S., Denery-Papini, S., Moneret-Vautrin, D.A., 2008 Wheat grain allergies: an update on wheat allergens. Eur. Ann. Allergy Clin. Immunol. 40 (3), 67-76.

Becker, D., Wieser, H., Koehler, P., Folck, A., Mühling, K.H., Zörb, C., 2012. Protein composition and techno-functional properties of transgenic wheat with reduced $\alpha$-gliadin content obtained by RNA interference. J. Appl. Bot. Food Qual. 85, 23-33.

Bernardo, D., Garrote, J.A., Nadal, I., Leon, A.J., Calvo, C., Fernandez-Salazar, L. Blanco-Quiros, A., Sanz, Y., Arranz, E., 2009. Is it true that coeliacs do not digest gliadin? Degradation pattern of gliadin in coeliac disease small intestinal mucosa. Gut 58, 886-887.

Bethune, M.T., Khosla, C., 2008. Parallels between pathogens and gluten peptides in celiac sprue. Plos Pathog. 4, e34.

Biesiekierski, J.R., Newnham, E.D., Irving, P.M., Barrett, J.S., Haines, M., Doecke, J.D. Shepherd, S.J., Muir, J.G., Gibson, P.R., 2011. Gluten causes gastrointestinal symptoms in subjects without celiac disease: a double-blind randomized placebo-controlled trial. Am. J. Gastroenterol. 106, 508-514.

Boussault, P., Léauté-Labrèze, C., Saubusse, E., Maurice-Tison, S., Perromat, M., Roul, S. Sarrat, A., Taïeb, A., Boralevi, F., 2007. Oat sensitization in children with atopic dermatitis: prevalence, risks and associated factors. Allergy 62, 1251-1256.

Breiteneder, H., Radauer, C., 2004. A classification of plant food allergens. J. Allergy Clin. Immunol. 113, 821-830.

Brouns, F.J.P.H., Van Buul, V.J., Shewry, P.R., 2013. Does wheat make us fat and sick? J. Cereal Sci. 58, 209-215.

Camarca, A., Anderson, R.P., Mamone, G., Fierro, O., Facchiano, A., Costantini, S. Zanzi, D., Sidney, J., Auricchio, S., Sette, A., Troncone, R., Gianfrani, C., 2009. Intestinal $\mathrm{T}$ cell responses to gluten peptides are largely heterogeneous: implications for a peptide-based therapy in celiac disease. J. Immunol. 182, 4158-4166.

Carroccio, A., Brusca, I., Mansueto, P., D’alcamo, A., Barrale, M., Soresi, M., Seidita, A., La Chiusa, S.M., Iacono, G., Sprini, D., 2012. A comparison between two different in vitro basophil activation tests for gluten- and cow's milk protein sensitivity in irritable bowel syndrome (IBS)-like patients. Clin. Chem. Lab. Med. 51, 1257-1263.

Cassidy, B.G., Dvorak, J., Anderson, O.D., 1998. The wheat low-molecular-weight glutenin genes: characterization of six new genes and progress in understanding gene family structure. Theor. Appl. Genet. 96, 743-750.

Catassi, C., Fasano, A., 2010. Celiac disease diagnosis: simple rules are better than complicated algorithms. Am. J. Med. 123, 691-693. 
Chertok, I.R., 2007. The importance of exclusive breastfeeding in infants at risk for celiad disease. MCN Am. J. Maternal Child Nurs. 32, 50-54.

Constantin, C., Quirce, S., Poorafshar, M., Touraev, A., Niggemann, B., Mari, A. Ebner, C., Akerström, H., Heberle-Bors, E., Nystrand, M., Valenta, R., 2009. Microarrayed wheat seed and grass pollen allergens for component-resolved diagnosis. Allergy 64, 1030-1037.

Denery-Papini, S., Lauriére, M., Branlard, G., Morisset, M., Pecquet, C., Choudat, D., Merlino, M., Pineau, F., Popineau, Y., Boulenc, E., Bouchez-Mahiout, I. Bodinier, M., Moneret-Vautrin, D.A., 2007. Influence of the allelic variants encoded at the Gli-B1 locus, responsible for a major allergen of wheat, on IgE reactivity for patients suffering from food allergy to wheat. J. Agric. Food Chem. 55, 799-805.

Denery-Papini, S., Pineau, F., Bodinier, M., Branlard, G., Faye, A., Tranquet, O., Larre, C., Monoret-Vautrin, D.A., 2009. Allergens and epitopes involved in food allergy to wheat and their presence in different wheat genotypes. In: Branlard, G. (Ed.), Gluten Proteins 2009. INRA, France, pp. 280-284.

Denery-Papini, S., Bodinier, M., Larré, C., Brossard, C., Pineau, F., Triballeau, S., Pietri, M., Battais, F., Mothes, T., Paty, E., Moneret-Vautrin, D.A., 2012. Allergy to deamidated gluten in patients tolerant to wheat: specific epitopes linked to deamidation. Allergy 67, 1023-1032.

DePaolo, R.W., Abadie, V., Tang, F., Fehlner-Peach, H., Hall, J.A., Wang, W. Marietta, E.V., Kasarda, D.D., Waldmann, T.A., Murray, J.A., Semrad, C. Kupfer, S.S., Belkaid, Y., Guandalini, S., Jabri, B., 2011. Co-adjuvant effects of retinoic acid and IL-15 induce inflammatory immunity to dietary antigens. Nature 471, 220-224.

Dørum, S., Qiao, S.W., Sollid, L.M., Fleckenstein, B., 2009. A quantitative analysis of transglutaminase 2-mediated deamidation of gluten peptides: implications for the T-cell response in celiac disease. J. Proteome Res. 8, 1748-1755.

Di Sabatino, A., Giuffrida, P., Corazza, G.R., 2013. Still waiting for a definition of nonceliac gluten sensitivity. J. Clin. Gastroenterol. 47, 567-569.

Elli, L., 2012. Where's the evidence for gluten sensitivity? Br. Med. J. 345, e7360.

Fasoli, E., Pastorello, E.A., Farioli, L., Scibilia, J., Aldini, G., Carini, M., Marocco, A. Boschetti, E., Righetti, P.G., 2009. Searching for allergens in maize kernels via proteomic tools. J. Proteomics 72, 501-510.

Fernandez-Feo, M., Wei, G., Blumenkranz, G., Dewhirst, F.E., Schuppan, D., Oppenheim, F.G., Helmerhorst, E.J., 2013. The cultivable human oral glutendegrading microbiome and its potential implications in coeliac disease and gluten sensitivity. Clin. Microbiol. Infect. 19, E386-E394.

Frisk, G., Hansson, T., Dahlbom, I., Tuvemo, T., 2008. A unifying hypothesis on the development of type 1 diabetes and celiac disease: gluten consumption may be a shared causative factor. Med. Hypotheses 70, 1207-1209.

Fresco, L.O., 2012. Hamburgers in Het Paradijs (in Dutch). Uitgeverij Bert Bakker.

Gao, Z.S., Shen, H.H., Zheng, M., Frewer, L.J., Gilissen, L.J.W.J. (Eds.), 2012. Multidisciplinary Approaches to Allergies. Zhejiang University Press and SpringerVerlag GmbH, ISBN 978-3-642-31608-1.

Garcia-Casado, G., Crespo, J.F., Rodriguez, J., Salcedo, G., 2001. Isolation and characterization of barley lipid transfer protein and protein $\mathrm{Z}$ as beer allergens. J. Allergy Clin. Immunol. 108, 647-649.

Gil-Humanes, J., Pistón, F., Tollefsen, S., Sollid, L.M., Barro, F., 2010. Effective shutdown in the expression of celiac disease-related wheat gliadin T-cell epitopes by RNA interference. Proc. Natl. Acad. Sci. U. S. A. 107, 17023-17028.

Gil-Humanes, J., Pistón, F., Giménez, M.J., Martín, A., Barro, F., 2012. The introgression of RNAi silencing of $\gamma$-gliadins into commercial lines of bread wheat changes the mixing and technological properties of the dough. PLoS One 7 , e45937.

Gilissen, L.J.W.J., Wichers, H.J., Savelkoul, H.F.J., Beers, G., 2006. Future developments in allergy prevention: a matter of intergrating medical, natural and social sciences. In: Gilissen, L.J.W.J., Wichers, H.J., Savelkoul, H.F.J., Bogers, R.J (Eds.), Allergy Matters. New Approaches to Allergy Prevention and Management, Wageningen UR Frontis Series, vol. 10. Springer, pp. 3-10.

Gilissen, L.J.W.J., Gao, Z.S., Chen, Z., 2012a. Multidisciplinary approaches to allergy prevention (2012) In: Gao Z S. Shen, H.H. Zheng M. Frewer, L.J., Gilissen, LJ.W.J. (Eds.), Multidisciplinary Approaches to Allergies. Zhejiang University Press and Springer-Verlag GmbH, ISBN 978-3-642-31608-1, pp. 33-55.

Gilissen, L.J.W.J., Van den Broeck, H.C., Londono, D.M., Salentijn, E.M.J., Koning, F, van der Meer, I.M., Smulders, M.J.M., 2012b. Food-related strategies towards reduction of gluten intolerance and gluten sensitivity. In: Koehler, P. (Ed.), 25th Meeting Working Group on Prolamin Analysis and Toxicity. German Research Centre for Food Chemistry, Freising, Germany, pp. 29-35. In: http://www. wgpat.com.ar/proceeding_25th.pdf.

Gilissen, L.J.W.J., Timmer, R.D., Van der Meer, I.M., Smulders, M.J.M., 2013a. Intestinal Health and Disease Prevention: a Story of Wheat and Oats. Food for Thought. www.nfia.com/fft/201302/.

Gilissen, L.J.W.J., Frewer, L.J., Gao, Z.S., 2013b. Multidisciplinary approaches to allergies. Food Sci. Technol. J. www.fstjournal.org/features/27-2/.

Goryunova, S.V., Salentijn, E.M.J., Chikida, N.N., Kochieva, E.Z., Van der Meer, I.M., Gilissen, L.J.W.J., Smulders, M.J.M., 2012. Expansion of the gamma-gliadin family in Aegilops and Triticum. BMC Evol. Biol. 12, 215.

Gourbeyre, P. Denery-Papini, S., Larré, C., Gaudin, J-C., Brossard, C., Bodiner, M. 2012. Wheat gliadins modified by deamidation are more efficient than native gliadins in inducing a Th2 response in Balb/c mice experimentally sensitized to wheat allergens. Mol. Nutr. Food Res. 56, 336-344.

Greco, L., Gobbetti, M., Auricchio, R., Di Mase, R., Landolfo, F., Paparo, F., Di Cagno, R. De Angelis, M., Rizzello, C.G., Cassone, A., Terrone, G., Timpone, L., D’Aniello, M., Maglio, M., Troncone, R., Auricchio, S., 2011. Safety for patients with celiac disease of baked goods made of wheat flour hydrolyzed during food processing. Clin. Gastroenterol. Hepatol. 9, 24-29.

Hollon, J.R., Cureton, P.A., Martin, M.L., Puppa, E.L., Fasano, A., 2013. Trace gluten contamination may play a role in mucosal and clinical recovery in a subgroup of diet-adherent non-responsive celiac disease patients. BMC Gastroenterol. 13, 40.

Husby, S., Koletzko, S., Korponay-Szabó, IR., Mearin, M.L, Phillips, A, Shamir, R. Troncone, R., Giersiepen, K., Branski, D., Catassi, C., Lelgeman, M., Mäki, M., Ribes-Koninckx, C., Ventura, A., Zimmer, K.P., ESPGHAN Working Group on Coeliac Disease Diagnosis, ESPGHAN Gastroenterology Committee, European Society for Pediatric Gastroenterology, Hepatology, and Nutrition, 2012. European Society for Pediatric Gastroenterology, Hepatology, and Nutrition guidelines for the diagnosis of coeliac disease. J. Pediatric Gastroenterol. Nutr. 54, 136-160. Erratum in: Journal of Pediatric Gastroenterology and Nutrition 54,572 .

Ivarsson, A., Hernell, O., Stenlund, H., Persson, L.A., 2002. Breast-feeding protects against celiac disease. Am. J. Clin. Nutr. 75, 914-921.

Ivarsson, A., Persson, L., Nyström, L., Ascher, H., Cavell, B., Danielsson, L., Dannaeus, A., Lindberg, T., Lindquist, B., Stenhammar, L., Hernell, O., 2000. Epidemic of coeliac disease in Swedish children. Acta Pædiatr. 89, 165-171.

Jeon, Y.H., Oh, S.J., Yang, H.J., Lee, S.L., Pyun, B.Y., 2011. Identification of major rice allergens and their clinical significance in children. Korean J. Pediatrics 54, 414-421.

Jones, J.M., Anderson, J.W., 2008. Grain foods and health: a primer for clinicians. Physician Sportsmed. 36, 18-33.

Junker, Y., Zeissig, S., Kim, S.J., Barisani, D., Wieser, H., Leffler, D.A., Zevallos, V., Libermann, T.A., Dillon, S., Freitag, T.L., Kelly, C.P., Schuppan, D., 2012. Wheat amylase trypsin inhibitors drive intestinal inflammation via activation of tolllike receptor 4. J. Exp. Med. 209, 2395-2408.

Kaukinen, K., Collin, P., Huhtala, H., Mäki, M, 2013. Long-term consumption of oats in adult celiac disease patients. Nutrients 5, 4380-4389.

Kasarda, D.D., 2013. Can an increase in celiac disease be attributed to an increase in the gluten content of wheat as a consequence of wheat breeding? J. Agric. Food Chem. 61, 1155-1159.

Kidd, P., 2003. Th1/Th2 balance: the hypothesis, its limitations, and implications for health and disease. Altern. Med. Rev. 8, 223-246.

Koning, F., 2008. Celiac Disease: across the threshold of tolerance. In: Fasano, A., Troncone, R., Branski, D. (Eds.), Frontiers in Celiac Disease. Pediatr Adolesc Med 12, 82-88. Basel, Karger.

Koning, F., 2012. Celiac disease: quantity matters. Semin. Immunopathol. 34, $541-549$.

Konitzer, K., Wieser, H., Koehler, P. 2013. Development of a non-immunogenical method for gluten quantification. In: Koehler, P. (Ed.), Proceedings of the 26th Meeting of the Working Group on Prolamin Analysis and Toxicity. Verlag Deutsche Forschungsanstalt für Lebensmittelchemie (DFA), ISBN 978-3938896-66-2, pp. 51-56.

Kratzer, W., Kibele, M., Porzner, M., Boehm, B.O., Koenig, W., Oeztuerk, S., Mason, R.A., Haenle, M.H., 2013. Prevalence of celiac disease in Germany: a prospective follow-up study. World J. Gastroenterol. 19, 2612-2620.

Lee, A.R., Ng, D.L., Dave, E., Ciaccio, E.J., Green, P.H., 2009. The effect of substituting alternative grains in the diet on the nutritional profile of the gluten-free diet. J. Hum. Nutr. Dietetics 22, 359-363.

Li, X.M., 2012. Traditional Chinese medicine for treating food allergy and associated eczema: from research to practice perspective. In: Gao, Z.S., Shen, H.H., Zheng, M., Frewer, L.J., Gilissen, L.J.W.J. (Eds.), Multidisciplinary Approaches to Allergies, Advanced Topics in Science and Technology in China. Springer, pp. 289-302.

Lindfors, K., Lähdeaho, M.L., Kalliokoski, S., Kurppa, K., Collin, P., Mäki, M., Kaukinen, K., 2012. Future treatment strategies for celiac disease. Expert Opin. Ther. Targets 16, 665-675.

Londono, D.M., Smulders, M.J.M., Visser, R.G.F., Gilissen, L.J.W.J., Hamer, R.J., 2014. Development of a standard test for dough-making properties of oat cultivars. J. Cereal Sci. 59 (1), 56-61.

Londono, D.M., van 't Westende, W.P.C., Goryunova, S., Salentijn, E.M.J., van den Broeck, H.C., van der Meer, I.M., Visser, R.G.F., Gilissen, L.J.W.J., Smulders, M.J.M., 2013. Avenin diversity analysis of the genus Avena (oat). Relevance for people with celiac disease. J. Cereal Sci. 58, 170-177.

Loponen, J., 2006. Prolamin Degradation in Sourdoughs. Academic dissertation. EKT series 1372. University of Helsinki, p. 77.

Matucci, A., Veneri, G., Dalla Pellegrina, C., Zoccatelli, G. Vincenzi, S., Chignola, R. Peruffo, A.D.B., Rizzi, C., 2004. Temperature-dependent decay of wheat germ agglutinin activity and its implications for food processing and analysis. Food Control 15, 391-395.

Mearin, M.L., Ivarsson, A., Dickey, W., 2005. Coeliac disease: is it time for mass screening? Best practice and research. Clin. Gastroenterol. 19, 441-452.

Metakovsky, E.V., 1991. Gliadin allele identification in common wheat, II. Catalogue of gliadin alleles in common wheat. J. Genet. Breed. 45, 325-344.

Mills, E.N.C., Marsh, J.T., Boyle, R., Hoffmann-Sommergruber, K., DuPont, D., Bartra, J., Bakalis, S., McLaughlin, J., Shewry, P.R., 2013. Literature Review: 'nonIgE-mediated Immune Adverse Reactions to Foods'. EFSA supporting publication 2013:EN-NNNN. The University of Manchester, p. 39.

Mitea, C., Salentijn, E.M.J., van Veelen, P., Goryunova, S.V., van der Meer, I.M., van den Broeck, H.C., Mujico, J.R., Monserrat, V., Gilissen, L.J.W.J., Drijfhout, J.W., Dekking, L., Koning, F., Smulders, M.J.M., 2010. A universal approach to eliminate antigenic properties of alpha-gliadin peptides in celiac disease. PloS One 5 , e15637. 
Molberg, O., Uhlen, A.K., Jensen, T., Solheim Flaete, N., Fleckenstein, B., ArentzHansen, H., Raki, M., Lundin, K.E.A., Sollid, L., 2005. Mapping of gluten T-cell epitopes in the bread wheat ancestors: implications for celiac disease. Gastroenterology 128, 393-401.

Morón, B., Bethune, M.T., Comino, I., Manyani, H., Ferragud, M., López, M.C., Cebolla, A., Khosla, C., Sousa, C., 2008. Toward the assessment of food toxicity for celiac patients: characterization of monoclonal antibodies to a main immunogenic gluten peptide. PLoS One 3, e02294.

Moroni, A.V., Dal Bello, F., Arendt, E.K., 2009. Sourdough in gluten-free breadmaking: an ancient technology to solve a novel issue? Food Microbiol. 26, 676-684.

Murch, S., Jenkins, H., Auth, M., Bremmer, R., Butt, A., France, S., Furman, M., Gillett, P., Kiparissi, F., Lawson, M., McClain, B., Morris, M.-A., Sleet, S. Thorpe, M., 2013. Joint BSPGHAN and Coeliac UK guidelines for the diagnosis and management of coeliac disease inn children. Arch. Dis. Child. 98, 806-811.

NPD, 2013. Percentage of U.S. Adults Trying to Cut Down or Avoid Gluten in Their Diets Reaches New High in 2013. www.npd.com.

Osman, A.A., Uhlig, H.H., Valdes, I., Amin, M., Méndez, E., Mothes, T., 2001. A monoclonal antibody that recognizes a potential coeliac-toxic repetitive pentapeptide epitope in gliadins. Eur. J. Gastroenterol. Hepatol. 13, 1189-1193.

Osorio, C., Wen, N., Gemini, R., Zemetra, R., Von Wettstein, D., Rustgi, S., 2012. Targeted modification of wheat grain protein to reduce the content of celiac causing epitopes. Funct. Integr. Genomics 12, 417-438.

Palacin, A., Quirce, S., Armentia, A., Fernández-Nieto, M., Pacios, L.F., Asensio, T., Sastre, J., Diaz-Perales, A., Salcedo, G., 2007. Wheat lipid transfer protein is a major allergen associated with baker's asthma. J. Allergy Clin. Immunol. 120, 1132-1138.

Pastorelli, C., Veiga, J., Charles, N., Voignier, E., Moussu, H., Monteiro, R., Benhamou, M., 2002. Phospholipid scramblase, a new effector of FcepsilonRI signaling in mast cells. Mol. Immunol. 38, 1235-1238.

Pastorello, E.A., Farioli, L., Pravettoni, V., Ispano, M., Scibola, E., Trambaioli, C., Giuffrida, M.G., Ansalini, R., Godovac-Zimmerman, J., Conti, A., Fortunato, D. Ortolani, C., 2000. The maize major allergen, which is responsible for foodinduced allergic reactions, is a lipid transfer protein. J. Allergy Clin. Immunol. 106, 744-751.

Pastorello, E.A., Farioli, L., Pravettoni, V., Scibilia, J., Conti, A., Fortunato, D., Borgovono, L., Bonomi, S., Primavesi, L., Ballmer-Weber, B., 2009. Maize food allergy: lipid-transfer proteins, endochitinases, and alpha-zein precursor are relevant maize allergens in double-blind placebo-contrlled maize-challengepositive patients. Anal. Bioanal. Chem. 395, 93-102.

Peräaho, M., Collin, P., Kaukinen, K., Kekkonen, L., Miettinen, S., Mäki, M., 2004. Oats can diversify a gluten-free diet in celiac disease and dermatitis herpetiformis. J. Am. Dietetic Assoc. 104, 1148-1150.

Piperno, D.R., Weiss, E., Holst, I., Nadel, D., 2004. Processing of wild cereal grains in the Upper Palaeolithic revealed by starch grain analysis. Nature 430, 670-673.

Pistón, F., Gil-Humanes, J., Rodríguez-Quijano, M., Barro, F., 2011. Down-regulating $\gamma$-gliadins in bread wheat leads to non-specific increases in other gluten proteins and has no major effect on dough gluten strength. PLoS One 6, e24754.

Pulido, O., Gillespie, Z., Zarkadas, M., Dubois, S., Vavasour, E., Rashid, M., Switzer, C., Benrejeb, S., 2009. Introduction of oats in the diet of individuals with celiac disease: a systematic review. In: Advances in Food and Nutrition Research, vol. 57. Elsevier Inc..

Quercia, O., Zoccatelli, G., Stefanini, G.F., Mistrello, G., Amato, S., Bolla, M., Emiliani, F., Asero, R., 2012. Allergy to beer in LTP-sensitized patients: beers are not all the same. Allergy 67, 1186-1189.

Rafalski, J.A., 1986. Structure of wheat gamm-gliadin genes. Gene 43, 221-229.

Rook, G.A.W., 2011. Hygiene and other early childhood influences on the subsequent function of the immune system. Dig. Dis. 29, 144-153.

Rook, G.A.W., 2012. Hygiene hypothesis and autoimmune diseases. Clin. Rev. Allergy Immunol. 42, 5-15.

Rubio-Tapia, A., Kyle, R.A., Kaplan, E.L., Johnson, D.R., Page, W., Erdtman, F., Brantner, T.L., Kim, W.R., Phelps, T.K., Lahr, B.D., Zinmeister, A.R., Melton, L.J., Murray, J.A., 2009. Increased prevalence and mortality in undiagnosed celiac disease. Gastroenterology 137, 88-93.

Sabelli, P.A., Shewry, P.R., 1991. Characterization and organization of gene families at the Gli-1 loci of bread and durum wheats by restriction fragment analysis. Theor. Appl. Genet. 83, 209-216.

Salcedo, G., Quirce, S., Diaz-Perales, A., 2011. Wheat allergens associated with Bakers' asthma. J. Investig. Allergol. Clin. Immunol. 21, 81-92.

Salentijn, E.M.J., Goryunova, S.V., Bas, N., van der Meer, I.M., van den Broeck, H.C., Bastien, T., Gilissen, L.J.W.J., Smulders, M.J.M., 2009. Tetraploid and hexaploid wheat varieties reveal large differences in expression of alpha-gliadins from homoeologous Gli-2 loci. BMC Genomics 10, 48.

Salentijn, E.M.J., Mitea, D.C., Goryunova, S.V., Van der Meer, I.M., Padioleau, I., Gilissen, L.J.W.J., Koning, F., Smulders, M.J.M., 2012. Celiac disease T-cell epitopes from gamma-gliadins: immunoreactivity depends on the genome of origin, transcript frequency, and flanking protein variation. BMC Genomics $13,277$.

Salentijn, E.M.J., Esselink, D.G., Goryunova, S.V., Van der Meer, I.M., Gilissen, L.J.W.J., Smulders, M.J.M., 2013. Quantitative and qualitative differences in celiac disease epitopes among durum wheat varieties identified through deep RNA-amplicon sequencing. BMC Genomics 14, 905. http://dx.doi.org/10.1186/1471-2164-14-905.

Sapone, A., Bai, J.C., Ciacci, C., Dolinsek, J., Green, P.H., Hadjivassiliou, M., Kaukinen, K., Rostami, K., Sanders, D.S., Schumann, M., Ullrich, R., Villalta, D., Volta, U., Catassi, C., Fasano, A., 2012. Spectrum of gluten-related disorders: consensus on new nomenclature and classification. BMC Med. 10, 13.
Scibilia, J., Pastorello, E.A., Zisa, G., Ottolenghi, A., Ballmer-Weber, B., Pravettoni, V., Scovena, E., Robino, A., Ortolani, C., 2008. Maize food allergy: a double-blind placebo-controlled study. Clin. Exp. Allergy 38, 1943-1949.

Shewry, P.R., Halford, N.G., 2002. Cereal seed storage proteins: structures, properties and role in grain utilization. J. Exp. Bot. 53, 947-958.

Sicherer, S.H., Sampson, H.A., 2010. Food allergy. J. Allergy Clin. Immunol. 125, S116-S125.

Sollid, L.M., Jabri, B., 2005. Is celiac disease an autoimmune disorder? Curr. Opin. Immunol. 17, 595-600.

Sollid, L.M., Qiao, S.W., Anderson, R.P., Gianfrani, C., Koning, F., 2012. Nomenclature and listing of celiac disease relevant gluten T-cell epitopes restricted by HLA-DQ molecules. Immunogenetics 64, 455-460.

Sotkovský, P., Sklenář, J., Halada, P., Cinová, J., Setinová, I., Kainarová, A., Goliáš, J. Pavlásková, K., Honzová, S., Tučková, L., 2011. A new approach to the isolation and characterization of wheat flour allergens. Clin. Exp. Allergy 41, 1031-1043.

Spaenij-Dekking, L., Kooy-Winkelaar, Y., Van Veelen, P., Drijfhout, J.W., Jonker, H., Van Soest, L., Smulders, M.J.M., Bosch, D., Gilissen, L.J.W.J., Koning, F., 2005 Natural variation in toxicity of wheat: potential for selection of nontoxic varieties for celiac disease patients. Gastroenterology 129, 797-806.

Stichting Voedselallergie: www.stichtingvoedselallergie.nl/.

Suligoj, T., Gregorini, A., Colomba, M., Ellis, H.J., Ciclitira, P.J., 2013. Evaluation of the safety of ancient strains of wheat in coeliac disease reveals heterogeneous smal intestinal T cell responses suggestive of coeliac toxicity. Clin. Nutr. 32, 1043-1049.

Szajewska, H., Chmielewska, A., Piescik-Lech, M., Ivarsson, A., Kolacek, S. Koletzko, S., Mearin, M.L., Shamir, R., Auricchio, R., Troncone, R., On behalf of the PREVENTCD Study Group, 2012. Systematic review: early infant feeding and the prevention of coeliac disease. Aliment. Pharmacol. Ther. 36, 607-618.

Tanner, G.J., Colgrave, M.L., Blundell, M.J., Goswami, H.P., Howitt, C.A., 2013a. Measuring hordein (gluten) in beer - a comparison of ELISA and mass spectrometry. PLoS One 8, e56452.

Tanner, G.J., Blundell, M.J., Colgrave, M.L., Howitt, C.A., 2013b. Quantification of hordeins by ELISA: the correct standard makes a magnitude of difference. PLoS One 8, e56456.

Tatham, A.S., Shewry, P.R., 2008. Allergens to wheat and related cereals. Clin. Exp. Allergy 38, 1712-1726.

Tjon, J.M.L., van Bergen, J., Koning, F., 2010. Celiac disease: how complicated can it get? Immunogenetics 62, 641-651.

Troncone, R., Auricchio, R., Granata, V., 2008. Issues related to gluten-free diet in coeliac disease. Curr. Opin. Clin. Nutr. Metab. Care 11, 329-333.

Tye-Din, J.A., Stewart, J.A., Dromey, J.A., Beissbarth, T., van Heel, D.A., Tatham, A. Henderson, K., Mannering, S.I., Gianfrani, C., Jewell, D.P., Hill, A.V.S. McCluskey, J., Rossjohn, J., Anderson, R.P., 2010. Comprehensive, quantitative mapping of T cell epitopes in gluten in celiac disease. Sci. Transl. Med. 2, 41ra51.

UCB - The UCB Institute of Allergy, 1997. European Allergy White Paper. UCB Pharmaceutical Sector, ISBN 2-87301-018-5.

USDA, 2013. www.ers.usda.gov/data-products/wheat-data.aspx.

Uvackova, L., Skulteti, L., Bekesova, S., McClain, S., Hajduch, M., 2013. MSE based multiplex protein analysis quantified important allergenic proteins and detected relevant peptides carrying known epitopes in wheat grain extracts. J. Proteome Res.. http://dx.doi.org/10.1021/pr400336f.

Vader, W., Kooy, Y., Van Veelen, P., De Ru, A., Harris, D., Benckhuijsen, W., Pena, S., Mearin, L., Drijfhout, J.W., Koning, F., 2002. The gluten response in children with celiac disease is directed toward multiple gliadin and glutenin peptides. Gastroenterology 122, 1729-1737.

Van den Broeck, H.C., America, A.H.P., Cordewener, J.H.G., Nessen, M.A., Gilissen, L.J.W.J., Van der Meer, I.M., 2013. Label free targeted detection and quantification of celiac disease stimulating epitopes by LC-MS. In: Book of Abstracts. Third International Symposium on Gluten-Free Cereal Products and Beverages, Vienna, ISBN 978-3-9503336-0-2, p. 28.

Van den Broeck, H.C., de Jong, H.C., Salentijn, E.M.J., Dekking, L., Bosch, D., Hamer, R.J., Gilissen, L.J.W.J., van der Meer, I.M., Smulders, M.J.M., 2010. Presence of celiac disease epitopes in modern and old hexaploid wheat varieties: wheat breeding may have contributed to increased prevalence of celiac disease. Theor. Appl. Genet. 121, 1527-1539.

Van den Broeck, H.C., Gilissen, L.J.W.J., Smulders, M.J.M., van der Meer, I.M. Hamer, R.J., 2011. Dough quality of bread wheat lacking alpha-gliadins with celiac disease epitopes and addition of celiac-safe avenins to improve dough quality. J. Cereal Sci. 53, 206-216.

Van den Broeck, H.C., America, A.H.P., Smulders, M.J.M., Bosch, D., Hamer, R.J. Gilissen, L.J.W.J., Van der Meer, I.M., 2009a. A modified extraction protoco enables detection and quantification of celiac disease-related gluten proteins from wheat. J. Chromatogr. B 877, 975-982.

Van den Broeck, H.C., van Herpen, T.W.J.M., Schuit, C., Salentijn, E.M.J., Dekking, L., Bosch, D., Hamer, R.J., Smulders, M.J.M., Gilissen, L.J.W.J., van der Meer, I.M., 2009b. Removing celiac disease-related gluten proteins from bread wheat while retaining technological properties: a study with Chinese Spring deletion lines. BMC Plant Biol. 9, 41.

Van der Meer, I.M., Mes, J.J., Weijn, A., Wichers, H., 2012. Immunomodulation by food. In: Gao, Z.S., Shen, H.H., Zheng, M., Frewer, L.J., Gilissen, L.J.W.J. (Eds.), Multidisciplinary Approaches to Allergies, Advanced Topics in Science and Technology in China. Springer, pp. 303-313.

Van Eckert, R., Berghofer, E., Ciclitira, P.J., Denery-Papini, S., Ellis, H.J., Ferranti, P., Goodwin, P., Immer, U., Mamone, G., Méndez, E., Mothes, T., Novalin, S., Osman, A. Rumbo, M., Stern, M., Thorell, L., Whim, A., Wieser, H., 2006. Towards a new gliadin reference material - isolation and characterisation. J. Cereal Sci. 43, 331-341. 
Van Herpen, T.W.J.M., Goryunova, S.V., van der Schoot, J., Mitreva, M. Salentijn, E.M.J., Vorst, O., Schenk, M.F., van Veelen, P.A., Koning, F., van Soest, L.J.M., Vosman, B., Bosch, D., Hamer, R.J., Gilissen, L.J.W.J., Smulders, M.J.M., 2006. Alpha-gliadin genes from the A, B, and D genomes of wheat contain different sets of celiac disease epitopes. BMC Genomics 7, 1.

Van Riemsdijk, L.E., Van der Goot, A.J., Hamer, R.J., Boom, R.M., 2011. Preparation of gluten-free bread using a meso-structured whey protein particle system. J. Cereal Sci. 53, 355-361.

Van Wijk, F., Hartgring, S., Koppelman, S.J., Pieters, R., Knippels, L.M.J., 2004. Mixed antibody and $\mathrm{T}$ cell responses to peanut and the peanut allergens Ara h 1, Ara h 2, Ara h 3 and Ara h 6 in an oral sensitization model. Clin. Exp. Allergy 34, $1422-1428$.

Varjonen, E., Savolainen, J., Mattila, L., Kalimo, K., 1994. IgE-binding components of wheat, rye, barley and oats recognized by immunoblotting analysis with sera from adult atopic dermatitis patients. Clin. Exp. Allergy 24, 481-489.

Venter, C., Skypala, I., Dean, T., 2008. Maize allergy: what we have learned so far. Clin. Exp. Allergy 38, 1844-1846.

Vincentini, O., Borrelli, O., Silano, M., Gazza, L., Pogna, N., Luchetti, R., De Vincenzi, M., 2009. T-cell response to different cultivars of farro wheat, Triticum turgidum ssp. dicoccum, in celiac disease patients. Clin. Nutr. 28, 272-277.

Volman, J.J., Ramakers, J.D., Plat, J., 2008. Dietary modulation of immune function by beta-glucans. Physiol. Behav. 94, 276-284.

Weichel, M., Glaser, A.G., Ballmer-Weber, B.K., Schmid-Grendelmeier, P., Crameri, R., 2006. Wheat and maize thioredoxins: a novel cross-reactive cereal allergen family related to baker's asthma. J. Allergy Clin. Immunol. 117, 676-681.

Wen, S., Wen, N., Pang, J., langen, G., Brew-Appiah, R.A.T., Mejias, J.H., Osorio, C., Yang, M., Gemini, R., Moehs, C.P., Zemetra, R.S., Kogel, K.H., Liu, B., Wang, X., Von Wettstein, D., Rustgi, S., 2012. Structural genes of wheat and barley 5-methylcytosine DNA glycosylases and their potential applications for human health. Proc. Natl. Acad. Sci. U. S. A. 109, 20543-20548.

Wikipedia, 2013. Wheat. http://en.wikipedia.org.

Wrangham, R., Cheney, D., Seyfarth, R., Sarmiento, E., 2009. Shallow-water habitats as sources of fallback foods for hominins. Am. J. Phys. Anthropol. 140, 630-642.

Zamakhchari, M., Wei, G., Dewhirst, F., Lee, J., Schuppan, D., Oppenheim, F.G., Helmerhorst, E.J., 2011. Identification of Rothia bacteria as gluten-degrading natural colonizers of the upper gastro-intestinal tract. PLoS One 6, e24455.

Zanini, B., Petroboni, B., Not, T., Di Toro, N., Villanacci, V., Lanzarotto, F., Pogna, N., Ricci, C., Lanzini, A., 2013. Search for atoxic cereals: a single blind, cross-over study on the safety of a single dose of Triticum monococcum, in patients with celiac disease. BMC Gastroenterol. 13, 92.

Zhernakova, A., Van Diemen, C., Wijmenga, C., 2009. F.19. The shared genetics of immune-related diseases - what genome-wide association studies reveal. Clin. Immunol. 131, S98-S99.

Zuidmeer, L., Goldhahn, K., Rona, R.J., Gislason, D., Madsen, C., Summers, C., Sodergren, E., Dahlstrom, J., Lindner, T., Sigurdardottir, S.T., McBride, D., Keil, T., 2008. The prevalence of plant food allergies: a systematic review. J. Allergy Clin. Immunol. 121, 1210-1218. 